\title{
Progress in entransy theory and its applications
}

\author{
CHEN LinGen \\ College of Power Engineering, Naval University of Engineering, Wuhan 430033, China
}

Received April 27, 2012; accepted July 26, 2012

\begin{abstract}
The entransy and entransy dissipation extremum principle proposed have opened up a new direction for the heat transfer optimization. The emergence and development of entransy theory are reviewed. Entransy theory and its applications are summarized from several aspects, such as heat conduction, heat convective, heat radiation, heat exchanger design and mass transfer, etc. The emphases are focused on four aspects, i.e., the comparison between entropy generation rate and entransy dissipation rate, the combination of entransy dissipation extreme principle with finite time thermodynamics, the combination of entransy dissipation extreme principle with the heat conduction constructal theory, and the combination of entransy dissipation extreme principle with the heat convective constructal theory. The scientific features of entransy theory are emphasized.
\end{abstract}

entransy theory, entransy dissipation extreme principle, entropy generation rate, finite time thermodynamics, constructal theory, generalized thermodynamic optimization

Citation: Chen L G. Progress in entransy theory and its applications. Chin Sci Bull, 2012, 57: 4404-4426, doi: 10.1007/s11434-012-5477-4

Influenced by oil crisis in the 1970's directly, the heat transfer enhancement was world-widely paid attention by the scientific community, and was quickly developed into one of very important branches in thermal science and technology fields. With the progress of social development ideas, such as sustainable development, low-carbon technology and low-carbon economy, the concept of heat transfer enhancement has developed into a broader scope concept of heat transfer optimization [1]. In the past 30 years, the basic theory of heat transfer optimization has been made considerable progresses, and finite-time thermodynamics, field synergy principle, constructal theory as well as entransy theory are the representative achievements. The emergences of these theories promoted the developments of thermodynamics and heat transfer. Finite-time thermodynamics, which combined thermodynamics, heat transfer and fluid mechanics, provided a theoretical fundament for performance optimizations of practical processes and devices with the constraints of a finite size and finite time. Field synergy principle unified the essential physical understandings of convective heat transfer and heat transfer enhancement phenomena, and provided a theoretical fundament for the development of heat transfer enhancement technology to achieve better energy saving effects. Constructal theory, which was called the thermodynamics of non-equilibrium system with configuration in the field of thermal science, provided a theoretical fundament for the unified descriptions of the generation of flow structures in natural organization and the designs of various flow structures. Fourier's law of heat conduction, Newton's law of cooling and Stephen-Boltzmann law of blackbody radiation only gave the concept of heat transfer rate, while the concepts of entransy and entransy dissipation lay the foundation of defining the concept of heat transfer efficiency which did not appear in the heat transfer theory before. Entransy theory provided a new theoretical fundament for heat transfer optimization, which is different from that of the entropy generation minimization.

\section{Emergence and development of the entransy theory}

For the shortcomings in existing theories of heat transfer, 
based on the essence of heat transport phenomenon, Guo et al. [2] defined heat transport potential capacity and heat transport potential capacity dissipation function, and pointed out that their physical meanings correspond to the total heat transfer capability and the dissipation rate of heat transfer capability. By analogy between heat conduction process and electrical conduction process, Guo et al. [3,4] pointed out that the heat transport potential capacity is a new physical quantity, which corresponds the electric potential and can describe the total heat transfer ability of an object, and termed it as entransy. The loss of heat transfer ability in heat transfer process was termed as entransy dissipation, and the entransy dissipation extremum principle was proposed. The entransy and entransy dissipation extremum principle proposed opened a new direction for heat transfer optimization, and overcame the limitations and inaccuracy to evaluate heat transfer performance by the concepts of traditional thermal resistance and entropy generation. By analogy heat transfer with mechanics and electrics, Guo [5] introduced some new physical quantities for thermal quantity, such as potential, potential energy, velocity and kinetic energy, established conservation equations of thermal movement, and further perfected the theoretical system of heat transfer.

Based on the classical analogy between processes of heat conduction and electrical conduction, Guo et al. [3-5] defined a new physical quantity-entransy, which phenomenologically corresponded to electrical energy in electrical capacitor (it was also called heat transport potential capacity in [2])

$$
E_{V h}=Q_{V h} T / 2,
$$

where $Q_{V h}=M c_{V} T$ is the constant volume heat capacity and $T$ is the temperature of the object.

Heat transfer efficiency (entransy transfer efficiency) was defined as [6]

$$
\eta=\frac{E_{V h, \text { in }}-E_{V h, \text { out }}}{E_{V h, \text { in }}} .
$$

The entransy dissipation rate per unit time and volume, i.e., the entransy dissipation function, was [3-5]

$$
\phi_{h}=-\dot{q} \cdot \nabla T=k(\nabla T)^{2},
$$

where $\dot{q}$ is the heat flux vector and $\nabla T$ is the temperature gradient.

The entransy dissipation rate of the whole volume is

$$
\dot{E}_{V h \phi}=\int_{V} \phi_{h} \mathrm{~d} V .
$$

Based on the concept of entransy dissipation rate, the equivalent thermal resistance of multi-dimensional complex heat conduction problems was further defined as [3-5]

$$
R_{h}=\dot{E}_{V h \phi} / \dot{Q}_{h}^{2},
$$

where $\dot{Q}_{h}$ is the heat flux through the boundary of the control volume. The corresponding mean temperature difference $\Delta \bar{T}$ is [3-5]

$$
\Delta \bar{T}=R_{h} \dot{Q}_{h}
$$

From the heat conduction differential equation, Cheng et al. [7] established the variational principle corresponding to entransy by the method of weighted residuals, and pointed out that the temperature difference achieved its minimum when the entransy dissipation rate achieved its minimum for a fixed heat flux. The expression is

$$
\dot{Q}_{h} \delta(\Delta T)=\delta \int_{V} \frac{1}{2} k(\nabla T)^{2} \mathrm{~d} V=0 .
$$

For the specified heat conduction temperature difference, the heat flux achieves its maximum as the entransy dissipation rate achieves its maximum. The expression is

$$
\Delta T \delta \dot{Q}_{h}=\delta \int_{V} \frac{1}{2} k(\nabla T)^{2} \mathrm{~d} V=0
$$

Refs. [3,4] summarized it as entransy dissipation extremum principle which states that "for a fixed boundary heat flux, the heat conduction process is optimized when the entransy dissipation is minimized (minimum temperature difference); while for a fixed boundary temperature, the heat conduction process is optimized when the entransy dissipation is maximized (maximum heat flux)". The entransy dissipation extremum principle can be concluded as the minimum thermal resistance principle $[3,4]$ which states that "for heat conduction problems with specified constraints (for instance, a limited amount of high conducting material in the substrate), the heat conduction of an object will reach its optimal (maximum heat flux for a fixed temperature difference or the minimum temperature difference for a fixed heat flux) if its equivalent thermal resistance of the domain achieves its minimal". The definition of equivalent thermal resistance and the establishment of minimum thermal resistance principle provided the scientific fundament for the performance evaluations of practical heat transfer processes and equipments.

Many scholars showed strong interesting in the entransy and the entransy dissipation extremum principle, and further expounded the physical meaning of entransy from physical mechanism of heat conduction and electrothermal simulation experiment. A series of in-depth researches have been carried out in various directions, such as heat conduction, heat convection and heat exchanger, mass transfer, complex transfer process, phase change and radiative heat transfer. According to a incomplete statistics, more than 100 related literatures had been published until August 2011, including monographs and corpuses [1,8], review articles [9-11] and 
doctoral dissertations [12-22].

\section{The connotations of entransy and entransy dissipation extremum principle}

Entransy represents the total heat transfer ability of an object. In the heat transfer process, heat is conserved, but the heat transfer ability-entransy is dissipative. Entransy dissipation in heat transfer is similar to the dissipation of mechanical energy in fluid flow process [1]. If the entransy dissipation in heat transfer process achieves its extremum, the heat transfer efficiency is the highest and the heat transfer process is the best. The equivalent thermal resistance defined based on entransy dissipation is an index to evaluate the overall heat transfer performance of the system which is suitable for complex heat conduction problems, such as multi-dimensional and unsteady state ones or those with the internal heat source. It is more universal than the thermal resistance defined based on the analogy of ohm's law (temperature difference divided by heat flux). The mean temperature difference of the system can be effectively reduced by taking the minimization of equivalent thermal resistance as optimization objective, and the overall heat transfer performance of the system can be optimized. The optimal performance obtained based on equivalent thermal resistance minimization corresponds to the highest heat transfer efficiency. It is obvious that the concepts of entransy and entransy dissipation reflect essential property of heat transfer, and are recent advances of the second law of thermodynamics. The entransy dissipation extremum principle lays a new foundation for heat transfer optimization theory, which is not only different from the traditional heat transfer enhancement techniques, but also different from the entropy generation minimization.

\section{Present status of entransy and entransy dis- sipation extremum principle}

The researches on entransy and entransy dissipation extremum principle can be divided into the following aspects.

\subsection{Physical meanings of entransy}

Han et al. [23] made the analogy among heat conduction system, elastic mechanics system and electrical system, and found that the three different systems have the same behavior in transport aspect. Han and Guo [24] proposed the concept of thermal work to describe the potential capacity in transfer process, and deemed that the potential capacity dissipative mechanism is that the thermal work made by the temperature of the heat releasing object is more than that of the heat absorbing one. Zhu et al. [25] established electro-thermal simulation device, and verified the entransy dissipation extremum principle of heat conduction optimization. The experiments showed that the distributions of the high thermal conductive material leading to the optimal heat conduction performance are in agreement with those of numerical simulation results. Cheng et al. [26,27] provided micro statement of entransy and the entransy decrease principle of heat transfer process in an isolated system. Hu and Guo $[6,28]$ defined the efficiency of heat transfer process [6] and proposed the concepts of system entransy and available entransy [28]. Liu et al. [29] and $\mathrm{Xu}$ [30] discussed the problems of thermodynamic foundation of entransy and entransy dissipation.

\subsection{Heat conduction}

Guo et al. [2] optimized the wire insulation layer cooling and volume-point cooling problems by taking the minimum dissipation principle of heat transport potential capacity (minimum entransy dissipation rate), and the results showed that the more uniform temperature gradient is, the smaller the heat transfer potential capacity dissipation and the higher heat transfer efficiency become. For volume-point cooling problem, Cheng et al. [31] compared the two different methods of entropy generation minimization and transfer potential capacity dissipation minimization by numerical calculations, and the results showed that the optimization based on transfer potential capacity dissipation minimization can be more effective to improve the heat transfer efficiency, while the optimization based on entropy generation minimization is actually to reduce exergy loss. For heat conductive plate and circular tube, Han and Guo [32] performed heat conduction optimization based on potential capacity dissipation and entropy generation, respectively, and the results showed that optimization based on potential capacity dissipation minimization required a constant temperature gradient along the heat transfer direction and the system achieved its maximum heat transfer ability; while the optimization based on entropy generation minimization required a constant gradient of natural logarithm of temperature along the heat transfer direction and the system achieved its minimum exergy loss. Zhang and Liu [33] established a geometric average temperature function to describe cooling effect, and compared it with the mean temperature difference based on entransy dissipation. Chen et al. [34] discussed the relationship between heat conduction irreversibility and thermal conductivity of porous medium based on entransy dissipation, and optimized the heat conduction process of porous medium. The results showed that thermal conductivity of porous media not only affected the heat transfer ability of porous media, but also its heat conduction irreversibility. Cheng et al. [35] discussed the uniformity problems of the temperature field and temperature gradient field.

\subsection{Heat convection}

For the fixed viscous dissipation, Meng [12] derived field 
synergy equations of steady laminar flow heat transfer by taking the heat transport potential capacity dissipation extremum as the optimization objective and using the variational method. Based on [12], some scholars used the entransy (heat transport potential capacity) dissipation extremum principle to carry out heat transfer optimizations of convective heat transfer processes. Su et al. [36,37] verified the correctness of the field synergy equation by adopting the laminar air convective heat transfer model with two-dimensional square cavity and comparing the heat transfer results of optimal velocity field and other flow fields. Numerical method was introduced to solve the convective heat transfer of the water in a cylinder with uniform internal heat source and boundary conditions similar with the actual mixer, and a velocity distribution with multiple vortexes and reasonable regulation was obtained. Meng et al. [38] derived the control equations of optimal velocity field for laminar convection heat transfer using the variational method, and pointed that the optimal flow field of maximum heat convection coefficient inside a tube should be multiple longitudinal vortex structure with uniform wall temperature condition. Wu et al. [39] derived the field synergy equation of laminar convective heat transfer with steady-state and without internal heat source based on minimum entropy generation and by using the method analogous to the deduction the field synergy equation when potential capacity dissipation achieved its extremum. They optimized the square cavity convective heat transfer problems based on two different criteria of entropy generation minimization and potential capacity dissipation extremum principle. The results showed that the heat transfer effect based on potential capacity dissipation extremum principle was better than that based on entropy generation minimization. Wei [40] determined the upper and lower bounds of the time-averaged entransy dissipation in turbulent convection with volumetric heat source, and the bounds reflect the effect of volumetric heat source on the entransy dissipation in turbulent convection. Chen and $\mathrm{Xu}$ [41] derived the local entransy dissipation formula of general convective heat transfer according to entransy dissipation, thermodynamics and fluid mechanics. Chen et al. $[42,43]$ analyzed the convective heat transfer with two different boundary conditions using entropy generation minimization principle and entransy dissipation extremum principle. They pointed out that entropy generation minimization principle should be adopted for the heat transfer problem aiming on reducing exergy loss, while entransy dissipation extremum principle should be adopted for that aiming on improving heat transfer ability. Chen and Ren [44] introduced the concepts of heat flux weighted average temperature and heat flux weighted average temperature difference of multi-dimensional heat transfer system, defined the ratio of heat flux weighted average temperature difference to total heat flux as a generalized thermal resistance of heat transfer process, and optimized the two-dimensional square cavity convective heat transfer process with constant wall temperature. Wang et al. [45] derived the entransy transfer equation, which was used for describing the multicomponent viscous flow system (including heat conduction, heat convection, mass transfer and chemical reaction processes), and discussed the heat transfer optimization theory and method by using entransy transfer equation in steadystate convective heat transfer process. Xu et al. [46] discussed the problem of entransy dissipation rate in convective heat transfer. Song et al. [47,48] discussed the optimization problems of convective heat transfer with flue gas condensation in rectangular passage and pipe.

\subsection{Heat exchanger}

Song et al. [49] optimized the heat transfer processes of one-dimensional two-stream and three-stream heat exchangers based on extransy dissipation extremum principle, and the results showed that the temperature difference field between hot and cold fluids should be completely uniform either perusing minimum entransy dissipation with fixed heat transfer quantity or perusing maximum heat transfer quantity with fixed entransy dissipation, which proved the correctness of the temperature difference field uniformity principle. Cheng et al. [50] established the relationship between the temperature difference field uniformity factor and the entransy-dissipation-based thermal resistance, found that the larger temperature difference field uniformity factor corresponded to the less thermal resistance as well as the larger effectiveness of heat exchanger, which proved the correctness of temperature difference field uniformity principle directly. Liu et al. [51] proposed the definitions of the equivalent thermal resistance and thermal resistance factor of heat exchangers based on entransy dissipation, established the heat exchanger analysis method based on this thermal resistance, and discussed the effects of number of heat transfer units and heat capacity ratio on the heat exchanger thermal resistance. Liu and Guo [52] and Guo et al. [53] established the relationship between heat transfer irreversibility and effectiveness by using the heat exchanger equivalent thermal resistance based on entransy dissipation, derived a unified functional relationship of heat exchanger effectiveness, equivalent thermal resistance and heat capacity ratio, and pointed out that it was suitable for heat exchangers with different flow process layout. $\mathrm{Xu}$ et al. [54] derived entransy dissipation caused by finite temperature difference heat transfer, fluid flow resistance and mixing of thermodynamic dissimilar fluids. Liu et al. [55] took two countercurrent heat exchangers as examples, i.e., the "only for the purpose of heat transfer" one and the "participating in irreversible Brayton cycle" one, and pointed out that the heat exchanger participating in the conversion of heat into work achieved its best when entropy generation achieved its extremum, while that only participating in heat transfer achieved its best when entransy dissipation achieved its extremum. Guo et al. [56] defined a physical quantity, 
entransy dissipation number, to evaluate heat exchanger performance. Chen et al. [57,58] derived the expressions of equivalent thermal resistance of heat exchanger networks with high and low temperatures based on entansy dissipation. Qian et al. [59] investigated three typical heat exchange networks, and found that the thermal resistance is a monotonic function of heat transfer quantity. Cheng et al. [60] defined the effectiveness of heat exchanger couple, compared the relationships among entropy generation, entransy dissipation, heat resistance and the effectiveness of heat exchanger couple, and found that only the heat resistance is a monotonic function of the effectiveness of heat exchanger networks. Guo et al. [61] proposed the entransy dissipation uniformity principle, applied the entransy dissipation extremum principle into the optimal design of shell tube and plate fin heat exchangers, and discussed the effect of viscous thermal effect in heat exchanger on the entransy dissipation [62-67]. The entransy dissipation performance of heat exchanger was further analyzed in [68].

\subsection{Radiative heat transfer}

In addition to heat conduction and convective heat transfer, radiative heat transfer is another important heat transfer mode. Wu et al. [16,69] introduced the concepts of entransy and entransy dissipation into radiative heat transfer, proposed the entransy dissipation extremum principle for radiative heat transfer optimization: "for a fixed boundary temperature, the radiative heat transfer is optimized when the entransy dissipation is maximized (maximum heat flux), while for a fixed boundary heat flux, the radiative heat transfer process is optimized when the entransy dissipation is minimized (minimum temperature difference)". They optimized the parallel plate with radiative heat transfer. Cheng et al. [70-73] performed the isothermal design of space radiation device, deduced the minimum radiative entransy loss principle, the radiative entransy dissipation extremum principle and minimum radiative thermal resistance principle for the closed radiative heat transfer system, and discussed the relationship between the entransy dissipation of thermal radiation and homogenization of temperature field for thermal radiator in space.

\subsection{Mass transfer}

Based on the analogy between mass transfer and heat transfer phenomenon and analogy to the definition of entransy dissipation function of heat transfer, Chen et al. [15,74-77] introduced the concept of mass entransy to describe the ability to transfer mass outside of an object, and defined the mass entransy dissipation function:

$$
\phi_{m}=-q_{m} \cdot \nabla Y=\rho D|\nabla Y|^{2},
$$

where $q_{m}$ is mass flow rate, $Y$ is component mass fraction, $\rho$ is density, and $D$ is mass diffusivity. Chen et al. [74-77] proposed the mass entransy dissipation (ever interpreted as mass transfer potential capacity dissipation function in [74]) extremum principle, and optimized various processes, such as laminar mass transfer [74], photocatalytic oxidation reactor, space station ventilation [76,77] and evaporative cooling systems [78-80], etc. Chen et al. [81] proposed the moisture resistance method for liquid desiccant performance analysis and optimization.

\subsection{Other applications}

The concepts of entransy and entransy dissipation were further applied into performance optimizations of transport network [82-84], spacecraft thermal control fluid parallel loop [85,86], lat-plate solar collectors [87], and district heating networks [88]. Cheng et al $[89,90]$ analyzed the physical phenomena of electrical conduction, heat transfer and mass transfer, summed up these into a generalized flow. They proposed the concepts of potential entransy, potential entransy flow and potential entransy dissipation in generalized flow in generalized flow, then developed potential entransy decrease principle, and finally established the potential balance criteria, i.e. the minimum potential entransy loss principle, potential entransy dissipation extremum principle and minimum generalized flow resistance principle. The entransy theory was extended to the generalized flow, which further extended the generalized flow by extending the entransy.

\section{Similarities and differences between entransy dissipation rate and entropy generation rate}

Since entransy was put forward as a new physical quantity to describe the heat transfer process, the comparison objective of entransy was always the entropy. There exist obvious differences in both the physical meanings and the description of heat transfer effect.

\subsection{Comparison of physical meanings between entropy generation rate and entransy dissipation rate}

(i) The physical meaning of entropy generation rate. Entropy is defined as $\mathrm{d} S=\delta Q / T$, that is, the entropy change of a system is equal to the ratio of heat exchange quantity between system and the outside world to system temperature in the irreversible process. Entropy increase principle shows that entropy never decreases in any process of the isolated system. Assuming that heat flux $\dot{q}$ is irreversibly transferred from the high-temperature heat source $T_{H}$ to the low temperature heat sink $T_{L}$, the entropy generation rate of the heat transfer process is

$$
\dot{S}_{\mathrm{gen}}=\dot{q}\left(\frac{1}{T_{L}}-\frac{1}{T_{H}}\right)=\frac{\dot{q} \Delta T}{T_{L}^{2}+T_{L} \Delta T} .
$$


Entropy generation rate is a parameter closely related to the second law of thermodynamics. The physical meanings of entropy generation rate in heat transfer process can be described by combing with the second law of thermodynamics.

The Clausius statement of the second law of thermodynamics is expressed as: Heat can not spontaneously transfer from the low temperature object to the high temperature object without paying the price. The Clausius statement of the second law of thermodynamics describes the irreversibility of heat transfer process. According to the Clausius statement of the second law of thermodynamics, if the heat flux $\dot{q}$ is transferred from heat sink $T_{L}$ to the heat source $T_{H}$, there must be input work from the outside. The heat flux $\dot{q}$ transferred is consisted of two parts: heat flux released by heat $\operatorname{sink} \dot{q}_{L}$ and input power $P$ from the outside world.

The Kelvin statement of the second law of thermodynamics is expressed as: It is impossible to produce a heat engine which absorbs heat from a single heat source and transform the heat all into work without any other changes. The Kelvin statement of the second law of thermodynamics points out that when the temperature difference between heat source $T_{H}$ and heat sink $T_{L}$ is $\Delta T$, if the heat flux released by heat source is $\dot{q}$, the power available between heat source and heat sink is $P$, and the heat flux absorbed by heat sink $T_{L}$ is $\dot{q}_{L}$. If the heat flux transferred from heat source $T_{H}$ to heat sink $T_{L}$ is $\dot{q}$, the power lost is $P$.

The Clausius statement and the Kelvin statement of the second law of thermodynamics are consistent. The power $P$ provided by outside world in the Clausius statement is equal to the power lost $P$ in the Kelvin statement, and they are called as the power loss. The heat transfer process with temperature difference $\Delta T$ is irreversible, and there must exist work ability loss. Entropy represents the work ability loss, and the entropy generation rate is the linear reflection of power loss $P$ in heat transfer process:

$$
P=\dot{q}\left(1-\frac{T_{L}}{T_{H}}\right)=\frac{\dot{q} \Delta T}{\left(T_{L}+\Delta T\right)}=T_{L} \cdot \dot{S}_{\mathrm{gen}} .
$$

(ii) The physical meanings of entransy dissipation rate [14]. Assuming the heat flux $\dot{q}$ irreversibly transfers from heat source $T_{H}$ to heat sink $T_{L}\left(\Delta T=T_{H}-T_{L}\right)$, according to eq. (4), the entransy dissipation rate of the heat transfer process is:

$$
\dot{E}_{h \phi}=\dot{q}\left(T_{H}-T_{L}\right)=\dot{q} \Delta T .
$$

According to phonon gas equation of state, Guo et al. [91] and Zhu et al. [14] established relationship between entransy and the energy of phonon gas thermal motion:

$$
\frac{1}{2} Q_{v h} T=\frac{c^{2}}{6 R} E_{c},
$$

$$
\frac{1}{2} Q_{v h} T=\frac{c^{2} V}{6 R \gamma} P_{c},
$$

where $E_{c}$ represents the thermal energy of equivalent mass of phonon gas, and $P_{c}$ represents the pressure of phonon gas.

Eq. (13) indicates that although the entransy is not the real energy, the amount of entransy is proportional to the energy of phonon gas thermal motion. When thermal motion energy is regarded as mass according to relativity massenergy formula, the energy produced by the thermal motion of the "thermal mass" has real physical meanings for energy, and its unit is $J$. Eq. (14) indicates that entransy is proportional to the pressure of phonon gas. The phonon gas pressure is the driving force to make the phonon gas flow. The phonon gas flow means transport of the energy. The higher the pressure, the stronger the trend of the phonon gas flows to the outside world, and the stronger the heat transfer ability of an object. Eq. (14) deeply reflects that entransy essentially represents the ability of an object to transfer heat outside, and entransy dissipation rate is the lost of this ability in the heat transfer process.

\subsection{Comparison between entransy dissipation rate and entropy generation rate in reflecting heat transfer effect}

According to eq. (10), entropy generation rate $\dot{S}_{\text {gen }}$ is not only related to $\Delta T$ and $\dot{q}$, but also the $T_{L}$. For given constant $\Delta T$ and $\dot{q}$, the relationship between $\dot{S}_{\text {gen }}$ and $T_{L}$ is shown in Figure 1. $\dot{S}_{\text {gen }}$ decreases as $T_{L}$ increases. For given constant $T_{L}$ and $\Delta T$, the relationship between $\dot{S}_{\text {gen }}$ and $\dot{q}$ is shown in Figure 2. $\dot{S}_{\text {gen }}$ linearly increases with the increase in $\dot{q}$. For given constants $T_{L}$ and $\dot{q}$, the relationship between $\dot{S}_{\text {gen }}$ and $\Delta T$ is shown in Figure 3. $\dot{S}_{\text {gen }}$ increases as $\Delta T$ increases, but not linear one. The increment decreases as $\Delta T$ increases.

According to eq. (12), entransy dissipation rate does not relate to $T_{L}$, but only relates to $\dot{q}$ and $\Delta T$. For given constant $\dot{q}, \dot{E}_{h \phi}$ linearly increases with the increase in $\Delta T$. For given constant $\Delta T, \dot{E}_{h \phi}$ linearly increases with the increase in $\dot{q}$. The relationship is shown in Figure 4 .

The problems of heat transfer enhancement are commonly divided into two cases: for given temperature difference boundary, heat transfer effect is improved as the heat flux increases; for given heat flux boundary, heat transfer effect is improved as the temperature difference decreases. By comparing the heat transfer enhancement objectives, i.e., entropy generation rate and entransy dissipation rate, one can derive the following conclusions $[3,4,92,93]$.

(1) Entropy generation rate is a quantity related to 


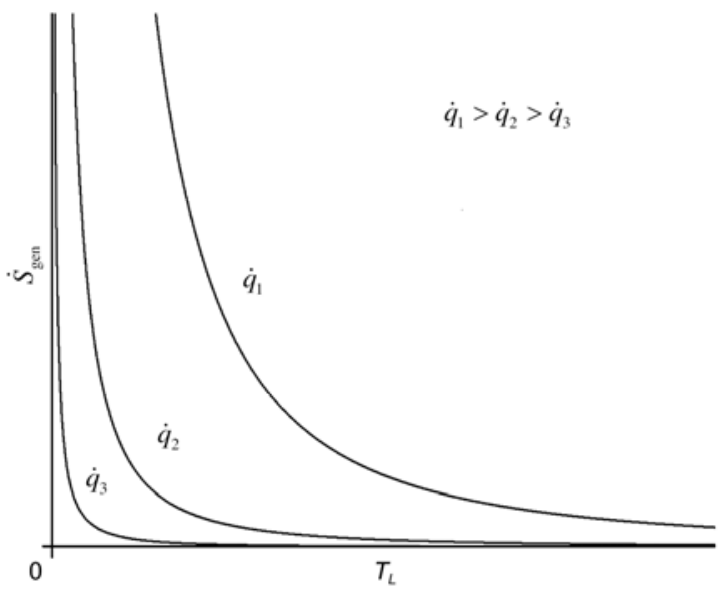

Figure 1 The relationship between $\dot{S}_{\text {gen }}$ and $T_{L}$ with constant $\Delta T$.

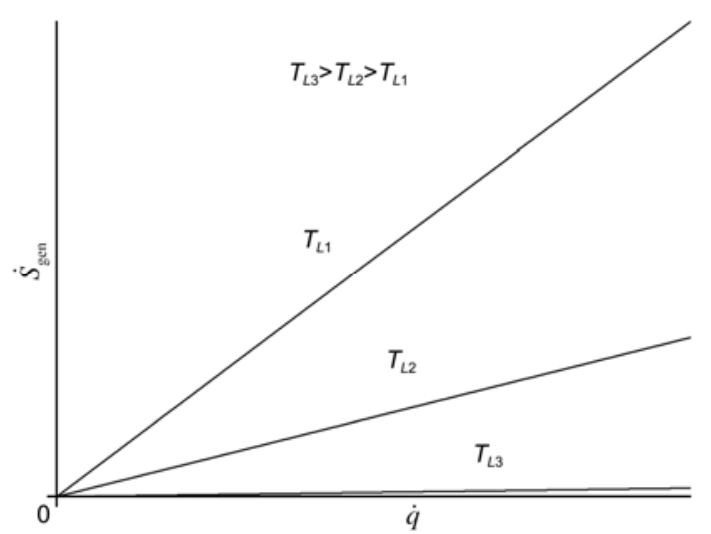

Figure 2 The relationship between $\dot{S}_{\text {gen }}$ and $\dot{q}$ with constant $\Delta T$.

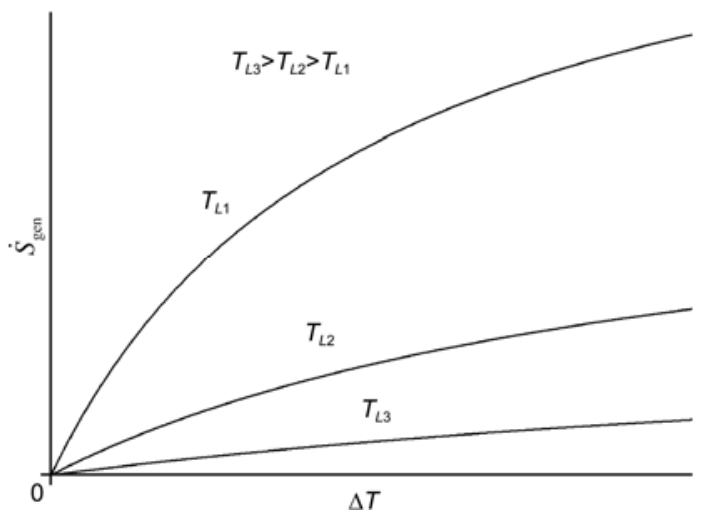

Figure 3 The relationship between $\dot{S}_{\text {gen }}$ and $\Delta T$ with constant $\dot{q}$.

environment temperature. For heat transfer processes with the same given heat flux and temperature difference but different environment temperatures, the heat transfer abilities are the same, but entropy generation rates are different. Entropy generation rate can not reflect the heat transfer ability for heat transfer processes with different environment temperatures. Entransy dissipation rate is only related

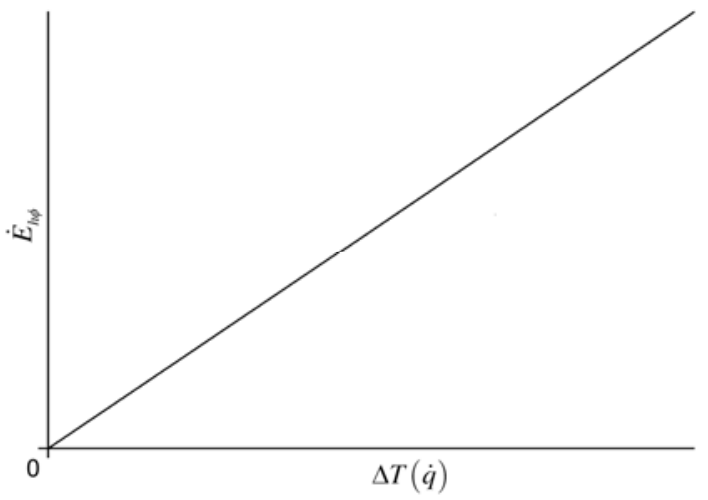

Figure 4 The relationship between $\dot{E}_{h \phi}$ and $\Delta T$ with constant $\dot{q}$ (The relationship between $\dot{E}_{h \phi}$ and $\dot{q}$ with constant $\Delta T$ ).

to heat flux and temperature difference, so it can reflect the heat transfer ability for heat transfer processes with different environment temperatures. These are shown in Figures 1 and 4.

(2) For heat transfer processes with the same given environment temperature and temperature difference, both entropy generation rate and entransy dissipation rate linearly increase with the increase in heat flux. Entropy generation rate and entransy dissipation rate are identical in reflecting the heat transfer ability. These are shown in Figures 2 and 4.

(3) For heat transfer processes with the same given environment temperature and heat flux, entropy generation rate increases as temperature difference increases, but the increment is becoming slower, and entropy generation rate will come close to a constant value $Q / T_{L}$. This means that entropy generation rate is not a linear function of temperature difference, while that of the entransy dissipation rate is a linear one, which is superior to entropy generation rate in describing heat transfer effect. These are shown in Figures 3 and 4.

(4) For heat transfer processes with small heat transfer temperature difference and the small temperature difference of the environment temperature, entropy generation rate can approximately and linearly reflect the change of temperature difference. Entropy generation rate and entransy dissipation rate are approximately identical in reflecting the heat transfer ability. These are shown in Figure 3.

(5) Minimum entropy generation rate corresponds to the optimization objective of minimum reciprocal of temperature (thermodynamic potential), while minimum entransy dissipation rate corresponds to that of minimum local temperature.

From the analyses mentioned above, without the premise to achieve minimum work loss, entransy dissipation rate is more suitable in describing heat transfer than entropy generation rate.

\section{Combination of entransy theory with finite- time thermodynamics}

The finite-time thermodynamics is a physical theory, which 
combines the heat transfer, fluid mechanics, thermodynamics and other transport sciences. It focuses on reducing the irreversibility of various transport processes with various finite potential differences (temperature difference, pressure difference, chemical potential difference, etc.) and the availability loss of the total system. The performances of practical processes, cycles and equipments with irreversibilities existing in the heat transfer, mass transfer, fluid flow and other transport phenomenon have been optimized with the constraints of finite-time and /or finite-size. It is also called as thermodynamic optimization or entropy generation minimization in engineering. Finite-time thermodynamics is widely used in the fields of heat transfer processes, heat engines, refrigerators, heat pumps, light-driven engine, quantum thermodynamic systems, direct energy conversion devices, fluid flow processes, heat exchangers, combustion and chemical reaction processes, thermal insulation systems, distillation and separation processes, energy storage systems and time-dependent on/off processes [94-114]. Obliviously, by combing entransy theory with finite-time thermodynamics to optimize heat and mass transfer processes, one can obtain different results [22,115-118].

\subsection{Entransy dissipation rate minimization for heat exchanger}

A class of two-fluid flow heat exchanger as shown in Figure 5 , in which the heat transfer between high- and low-temperature sides obeys Newton's heat transfer law $[q \propto \Delta(T)]$, was investigated. By taking entransy dissipation minimization as optimization objective, the optimum parameter distributions in heat exchanger were derived by using optimal control theory under the condition of fixed heat load, and were compared with those by taking entropy generation minimization as optimization objective. The results showed that the heat flux density corresponding to the minimum entransy dissipation is a constant, i.e. the temperature difference between the hot and cold fluids is a constant. It means that the result obtained coincided with the uniformity

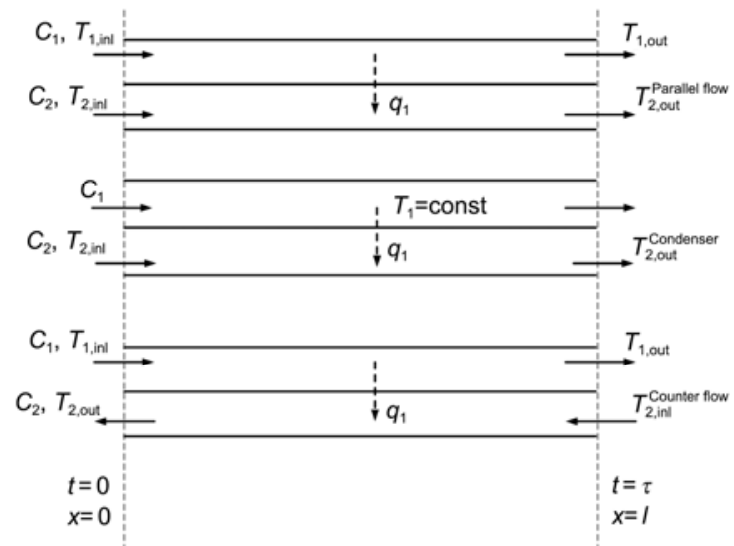

Figure 5 Three types of simple two-fluid heat exchanger models. principle of temperature difference field.

For the fixed heat load and Newton's law heat transfer processes, the temperature ratio of hot to cold fluids corresponding to the minimum entropy generation is constant, while the condition corresponding to the minimum entransy dissipation is constant heat flux density. The obtained results for these two different optimization objectives are remarkably different from each other. The results for entransy dissipation minimization and entropy generation minimization are close to each other when the heat load of the heat exchanger is small, as shown in Figures 6 and 7 [115].

\subsection{Entransy dissipation minimization for heat trans- fer processes with generalized radiative heat transfer law}

A class of finite-time heat transfer processes between highand low-temperature sides with the generalized radiative heat transfer law [ $\left.q \propto \Delta\left(T^{n}\right)\right]$ was investigated. Under the condition of fixed heat load, the optimal configurations of hot and cold fluid temperatures for minimizing entransy

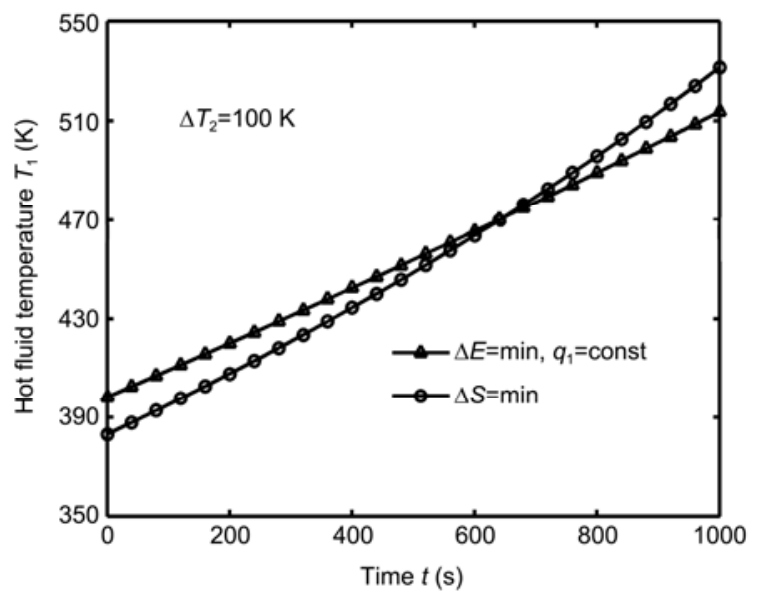

Figure 6 Optimal configuration of the hot fluid temperature with middle heat load $\left(\Delta T_{2}=100 \mathrm{~K}\right)$.

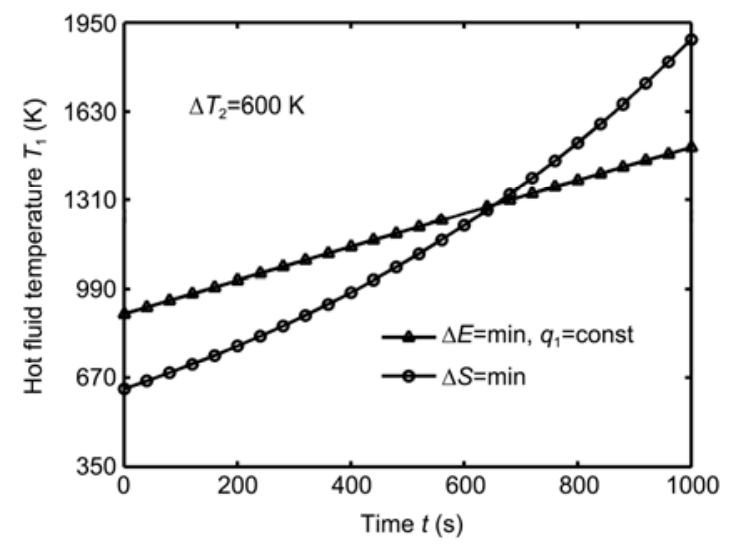

Figure 7 Optimal configuration of the hot fluid temperature with large heat load $\left(\Delta T_{2}=600 \mathrm{~K}\right)$. 
dissipation were derived. The results showed that [116]:

(1) For Newtonian law heat transfer processes, the heat flux density corresponding to minimum entransy dissipation is a constant, which coincides with the uniformity principle of temperature difference field, while the ratio of hot to cold fluid temperatures corresponding to minimum entropy generation is a constant.

(2) For linear phenomenological law heat transfer processes, the ratio of hot to cold fluid temperatures corresponding to minimum entransy dissipation is a constant, and the reciprocal temperature difference corresponding to minimum entropy generation is a constant, which is identical with the strategy of constant heat flux operation.

(3) For small heat load, i.e. the low heating temperature difference case of cold fluid, the differences between the optimal configuration of the fluid temperature for entransy dissipation minimization and that for entropy generation minimization are small, while for the large heat load case, the differences between them become remarkable.

(4) For radiative law heat transfer processes, the differences among three heating strategies, i.e. constant heat flux, entropy generation minimization and entransy dissipation minimization, are smaller than those for the cases with Newtonian and linear phenomenological heat transfer laws. The constant hot fluid temperature strategy leads to the largest entropy generation and entransy dissipation, i.e. the worst heat transfer effect.

\subsection{Entransy dissipation minimization for liquid-solid phase change processes}

The liquid-solid phase change process of a simple one-dimensional slab as shown in Figure 8 was investigated. By taking entransy dissipation minimization as optimization objective, the optimal external reservoir temperature profiles were derived by using optimal control theory under the condition of a fixed freezing or melting time. The results obtained for entransy dissipation minimization were also compared with those obtained for the optimal strategy of minimum entropy generation. The results showed that [117]:

(1) The entransy dissipation corresponding to the optimal heat exchange strategies of minimum entransy dissipation is $8 / 9$ of that corresponding to constant reservoir temperature operations, which is independent of all system parameters.

(2) For the optimal heat exchange strategies of minimum entransy dissipation, both the phase boundary velocity versus phase boundary position and the phase boundary position versus time during the slab freezing process are the same as those during the slab melting process. While for the optimal heat exchange strategies of minimum entropy generation, both the phase boundary velocity versus phase boundary position and the phase boundary position versus time during the slab freezing process are different from those during the slab melting process. Besides, the optimal external reservoir temperature profiles for the optimal heat

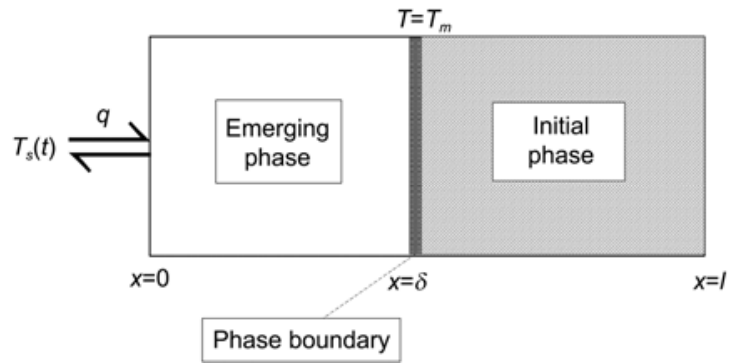

Figure 8 A simple one-dimensional slab liquid-solid phase change process model.

exchange strategies of these two different optimization objectives are also different, and the difference between them increases with the increase of parameter $\tau_{f} / t_{0}$ as shown in Figure 9. Entropy generation minimization denoted the minimum lost available energy, while entransy dissipation minimization denotes the least dissipation of heat transfer ability. All of practical liquid-solid phase change processes are independent of the heat-work conversion, so the optimization principle should be entransy dissipation minimization.

\subsection{Entransy dissipation minimization for one-way isothermal mass transfer processes}

A class of one-way isothermal mass transfer processes with
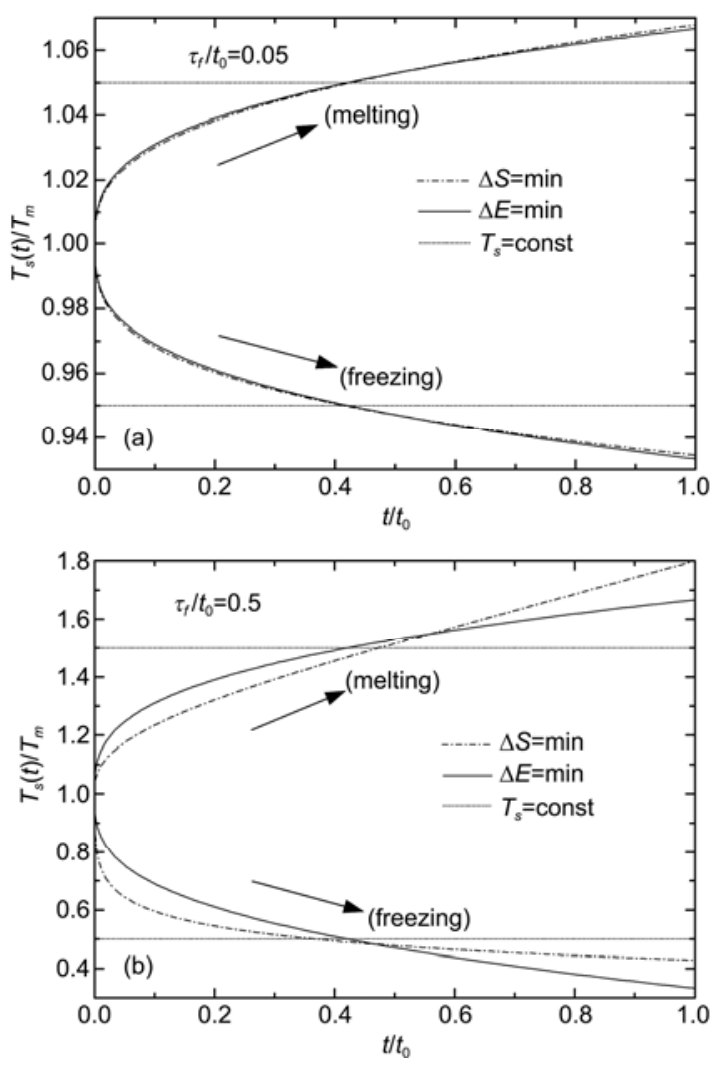

Figure 9 The dimensionless external heat reservoir temperature versus dimensionless time for different heat exchange strategies. (a) $\tau_{f} / t_{0}=0.05$; (b) $\tau_{f} / t_{0}=0.5$. 
Fick's diffusive mass transfer law $[g \propto \Delta(c)]$ as shown in Figure 10 was investigated. Based on the definition of the mass entransy, the mass entransy dissipation function which reflects the irreversibility of mass transfer ability loss was derived. The optimal concentration allocations of the key components corresponding to the high- and the low-concentration sides for the minimum mass entransy dissipation of the mass transfer process were obtained by applying optimal control theory, and this strategy was compared with those of the minimum entropy generation, constant mass transfer flux (constant concentration difference) and constant concentration ratio (constant chemical potential difference). The results showed that the optimal mass transfer strategy for the minimum mass entransy dissipation is that the product of the square of the key component concentration difference between the high- and low-concentration sides and the inert component concentration at the lowconcentration side is a constant, while for the minimum entropy generation the ratio of the square of the key component concentration difference between the high- and low-concentration sides to the key component concentration at the low-concentration side is a constant. When the mass transfer process is not involved in energy conversion process, the optimization principle should be the minimum mass entransy dissipation. The mass entransy dissipation of the mass transfer process for the strategy of constant concentration difference is smaller than that for the strategy of constant concentration ratio, so the former is superior to the latter [118].

\section{Combination of entransy theory with heat conduction constructal optimization}

In 1996, Professor Bejan of Duke University noted the crisscross of the city streets, which presented certain regularity. The major street networks of the worldwide big cities were very similar, and there existed a profound reason. He analyzed that the process of urban development, had two travel speeds in general: very slow speed (such as walking) and fast speed (such as carriage or vehicle speed). The uneven widths of the street were the result of the long time evolution on considering these two speeds simultaneously, which made the average travel speed of the city residents reached its optimum. After building the model and carrying

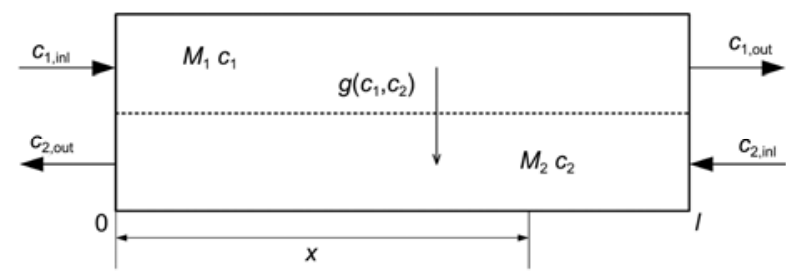

Figure 10 Model of one-way isothermal mass transfer process. out mathematical analysis of the formation and development of the street networks, Bejan proposed the constructal theory [119], and firstly used it in the research of cooling electronic components by optimizing the distribution of high thermal conductivity material (volume-point problem) [120]. He proposed the constructal law: "For a finite-size flow system to persist in time (to live), its configuration must change in time such that it provides easier and easier access to its currents." Or more simply stated as: the structures of matters come from their optimal performances.

The so-called "flow system" and "flow" have a broad meaning. The former includes all kinds of life bodies in nature and their tissues and organs, non-life systems and subsystems (such as river networks, atmospheric circulation, ocean currents, cracks, etc.) and various processes and devices in engineering. The latter includes thermal current, fluid flow, electrical current, mass flow, people and traffic flows, goods flow, etc. "Optimal performance" includes the minimum thermal resistance, the minimum entropy generation, the minimum flow resistance, the minimum pumping power, the minimum electric resistance, the fastest speed, the minimum transportation cost, the maximum profit rate, and so forth. The constructal theory explains the profound reasons of the flow structures generated in the fields of nature and society on the one hand, it guides to design the flow structure of various disciplines based on a unified physical principle (constructal law) on the other hand. Therefore, the constructal theory was termed as a new geometry philosophy. The constructal theory has been booming since it was proposed, and many scholars have shown great interests in the constructal theory. Plentiful of researches have been carried out about this theory, and its content has been greatly enriched. The fields covered by the constructal theory are large, such as heat and mass transfer, fluid flow, electricity, magnetism, transport, piping network, weathering dry, economic decision-making, weather forecasting, geophysical problem, economic transportation, product platform design, plant and animal structures and physiology, university ranking and other social dynamics problems, medical problem, security and sustainability issues, modern urban scale rate, pedestrian dynamics, organism aggregation, circulation market dynamics, coastal beach morphology, etc. [121-150]. Obviously, by combining entransy theory with constructal theory to optimize various processes based on extremum entransy dissipation rate (maximum or minimum), one can obtain different results [18,20,151-171].

The combination of entransy theory with heat conduction constructal optimization mainly includes volume-point heat conduction optimization, disc cooling optimization, crosssection optimization of round tube heat exchanger, multidisciplinary and multi-objective optimization of electromagnet and numerical optimization of cavity cooling. The minimization of maximum temperature difference was chosen as the optimization objective in the traditional studies of 
constructal theory, but the minimization of maximum temperature difference was the optimal result of a local one in the multi-scale heating object. The equivalent thermal resistance defined based on entransy dissipation rate reflects the heat conduction ability in the heat transfer process. The smaller the equivalent thermal resistance, the better the conductive effect, and the lower the mean temperature in the volume. The optimal constructs obtained based on minimization of entransy dissipation rate were the optimization results of the average heat transfer performance, which is different from the optimal constructs obtained based on minimization of maximum temperature difference.

\subsection{Volume-point heat conduction optimization}

The "volume to point" heat conduction problem can be described as how to determine the optimal distribution of high conductivity material through the given volume such that the heat generated at every point is transferred most effectively to its boundary. The research idea used was the same as that proposed by Bejan: assumed that the volume of high conductivity material to fill is fixed, firstly the element is optimized, and the optimal shape (aspect ratio) is obtained; then, several optimal elements are assembled to produce first assembly, the shape (or number of rectangular elements) and the high conductivity material distribution are optimized to minimize the entransy dissipation rate of first assembly; with similar work continued, after several assembling and optimization, the control volume will be covered by high order assembly, as shown in Figure 11. There were six aspects in "volume to point" heat conduction constructal optimization. (1) The process of rectangular element constructal optimization is shown in Figure 12 [151]. (2) The process of rectangular element constructal optimization without the premise of optimized last-order construct is shown in Figure 13 [152]. (3) The process of constructal

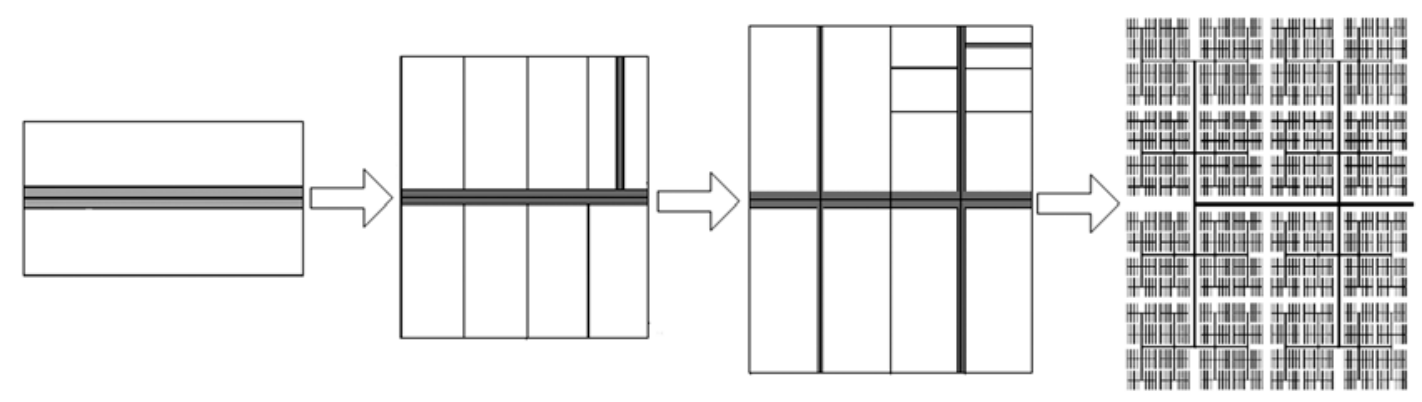

Figure 11 Volume-point heat conduction constructal optimization process.

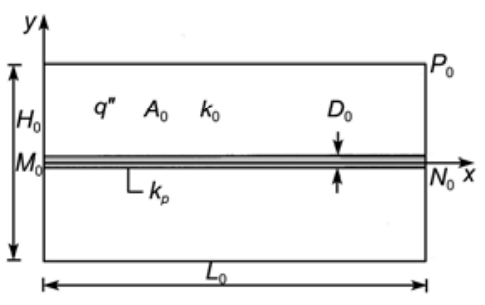

Element

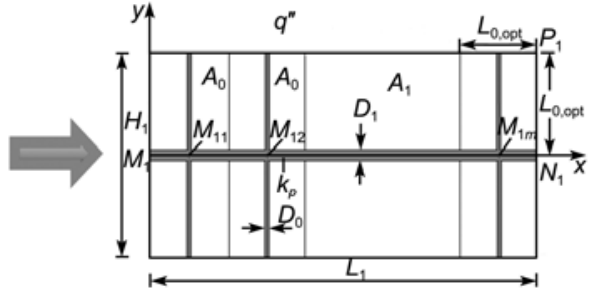

First assembly

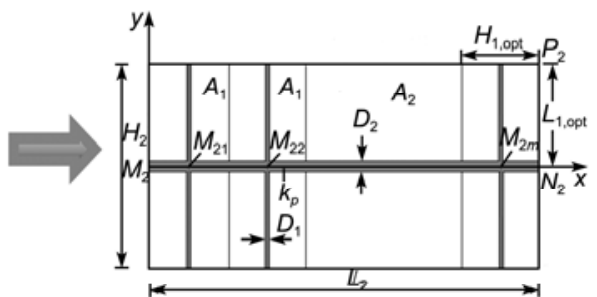

Second assembly

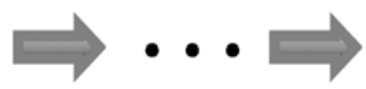

Selecting the construct with minimum entransy dissipation

Figure 12 Constructal optimization based on rectangular element.

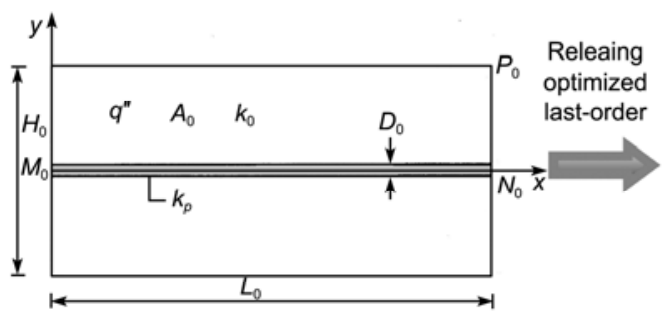

Element

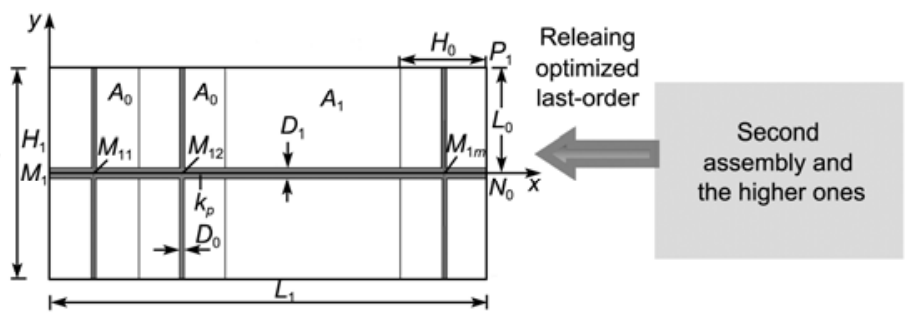

First assembly

Figure 13 Constructal optimization based on rectangular element without the premise of optimized last-order construct. 
optimization based on triangular element is shown in Figure 14 [153]. (4) The process of discrete variable conducting path contructal optimization based on fixed conducting path element is shown in Figure 15 [18]. (5) The process of discrete variable conducting path contructal optimization based on variable conducting path element is shown in Figure 16
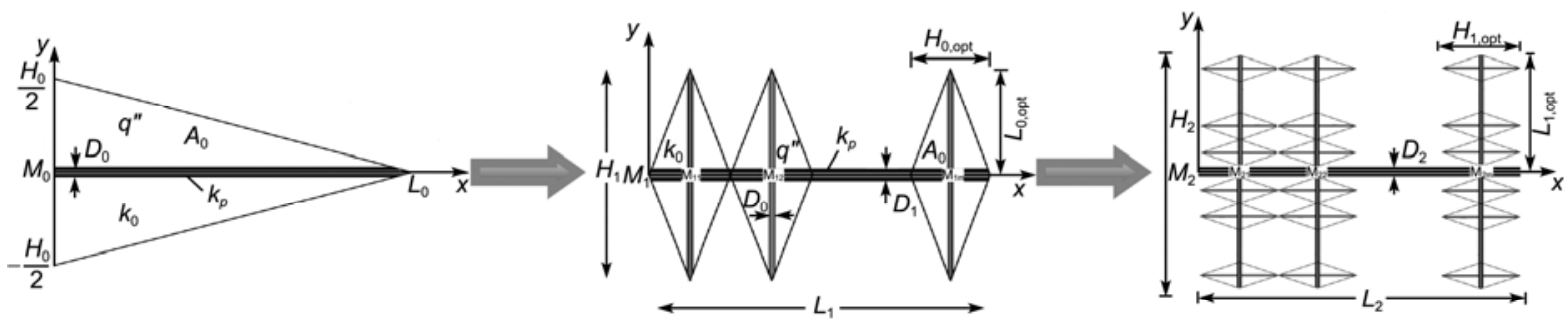

Element

First assembly

Second assembly

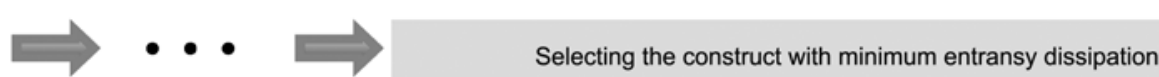

Figure 14 Constructal optimization based on triangular element.
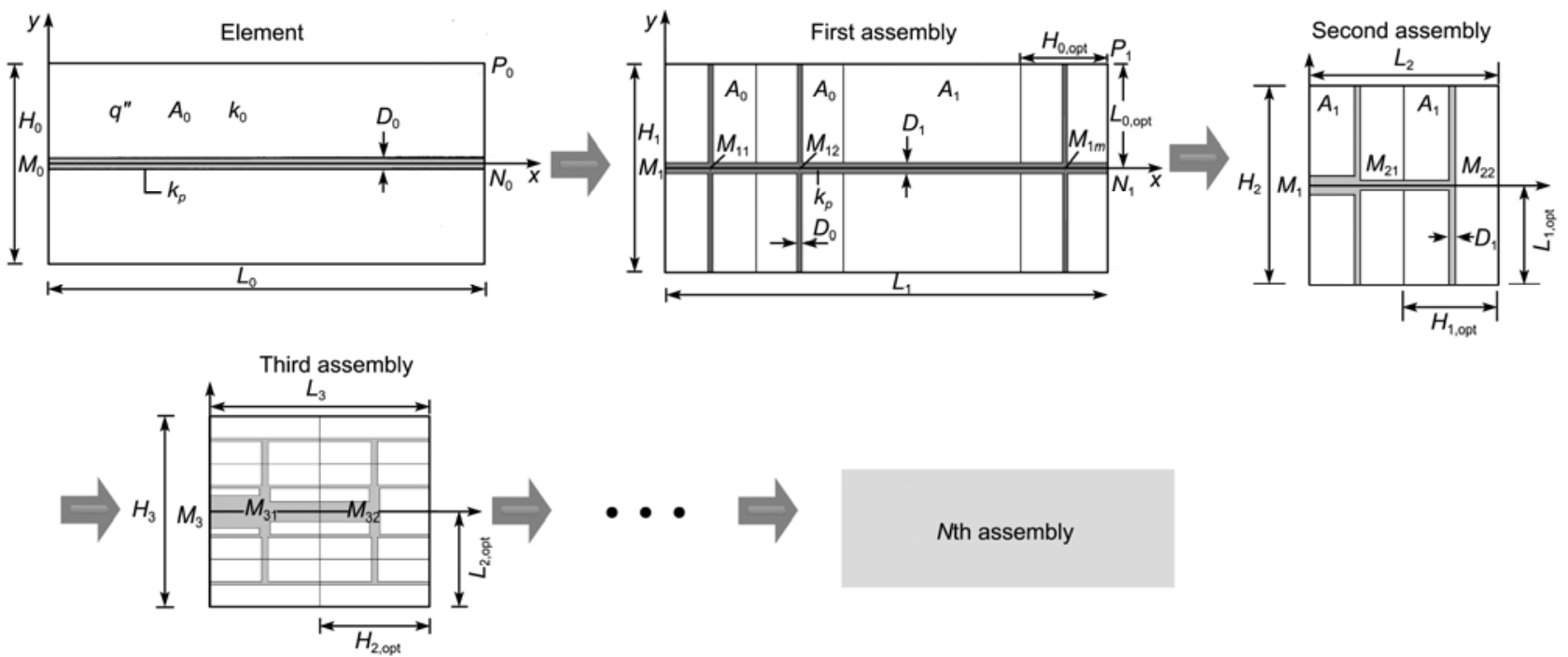

Nth assembly

Figure 15 Constructal optimization discrete variable conducting path contructal optimization based on fixed conducting path element.
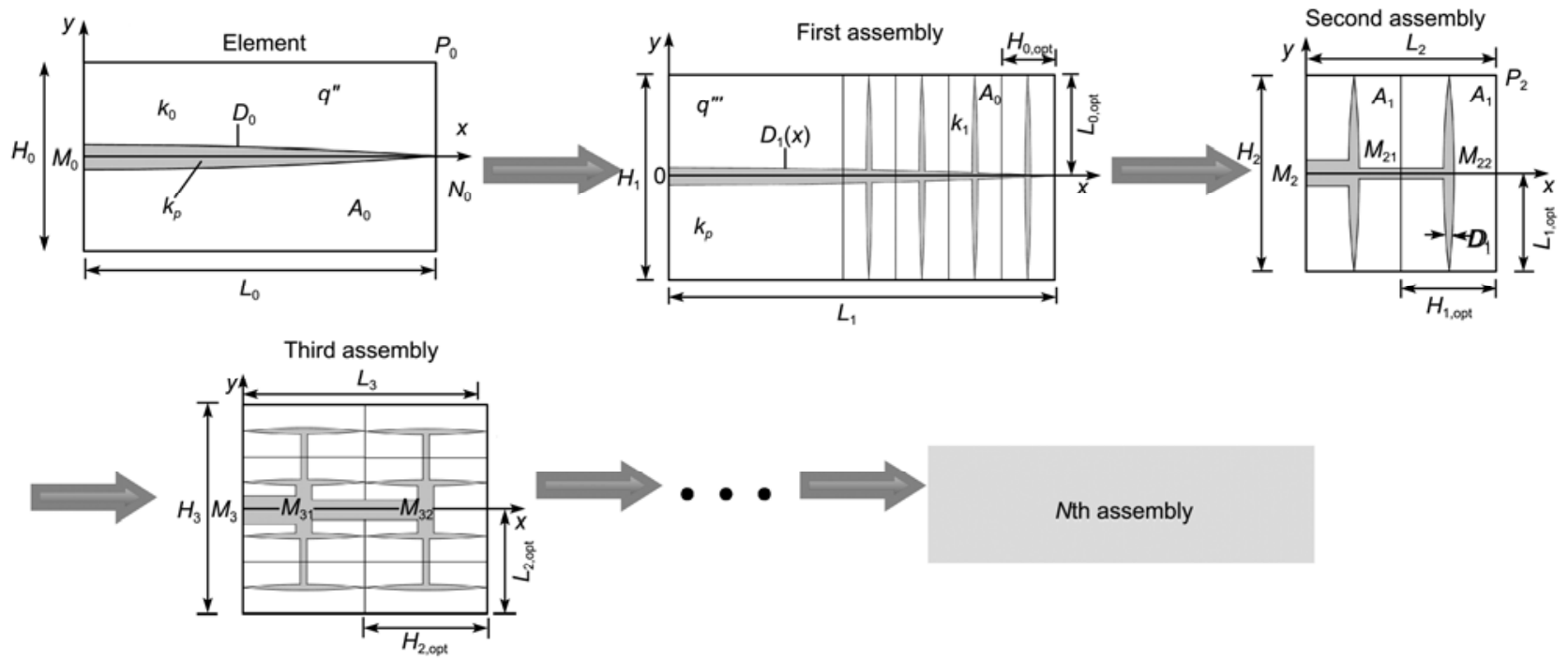

Nth assembly

Figure 16 Discrete variable conducting path contructal optimization based on variable conducting path element. 
[154]. (6) The process of constructal optimization based on variable cross-section shape and variable high conducting path element is shown in Figure 17 [155].

Analyzing the volume-point heat conduction model, one can obtain the following conclusions:

(1) The constructs based on entransy dissipation rate minimization can decrease the mean temperature difference. When the thermal current density in the high conductive path is linear with the length, the optimal constructs based on entransy dissipation rate minimization are the same as those based on the maximum temperature difference minimization. When the thermal current density in the high conductive path is nonlinear with the length, the optimal constructs based on entransy dissipation rate minimization are different from those based on maximum temperature difference minimization.

(2) A self similar conctructal optimization method was proposed, which can be described as follows: the heat transfer performance of an object is determined by the heat transfer performance, aspect ratio and the style of assembling the fundamental element. If there exists an assembling style which can improve its heat transfer performance while keeping the aspect ratio constant, then using the assembling style iteratively can achieve its corresponding maximal performance. This method revised the constructal optimization method proposed by Bejan, with which the heat transfer performance could not be improved through assembling. Currently, the realization of self similar constructal optimization based on entransy dissipation minimization includes two constructal modes: without the premise of optimal lastorder conctruct and discrete variable high conducting path.

\subsection{Disc cooling optimization}

(i) Radial high conducting fins inserted model [156]. The disc cooling model is shown in Figure 18. The heat is generated uniformly in the disc, and the disc can be regarded as uniform internal heat source. The total heat flux is transferred to the outside through the $N$ fins which are distributed uniformly on the disc, and the remaining parts are adiabatic.

By analyzing the disc cooling model inserted with radial high conducting fins, one can conclude: when the heat transfer performance of the disc achieves its best, the high conductive fin should extend to the center of the circle as
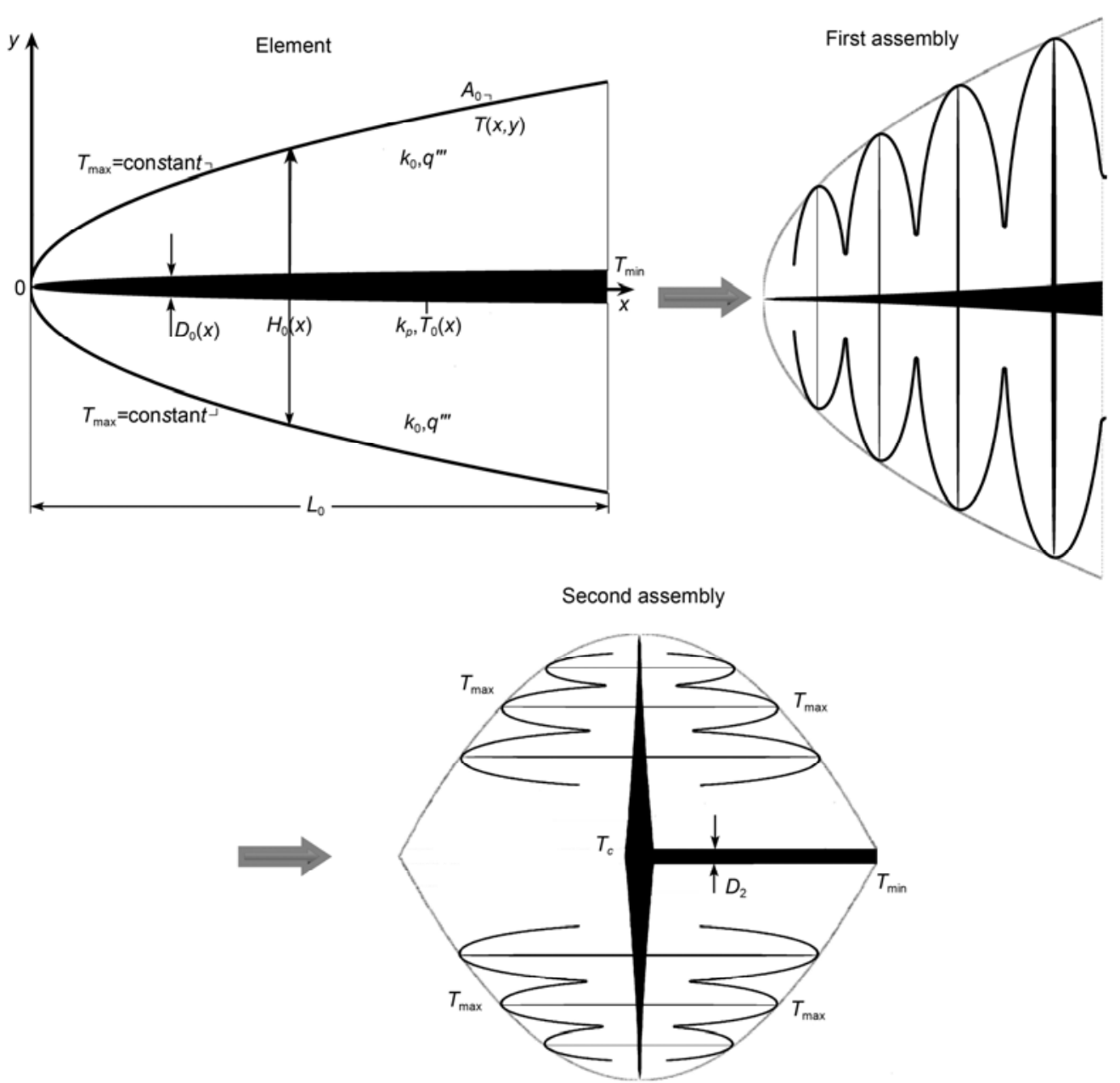

Figure 17 Constructal optimization based on variable cross-section shape and variable high conducting path element. 


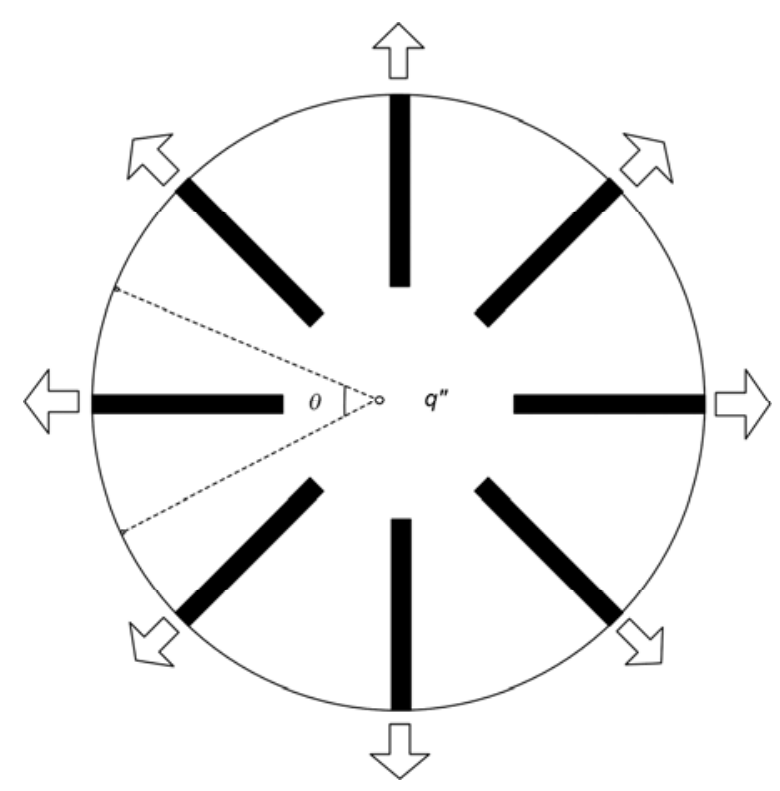

Figure 18 Radial high conductivity fins extending inward from rim.

the conductive effect of the fins is improved. The optimal ratio of the length of high conducting fins to radius of the circle is less affected by the high conducting fin number. The bigger the ratio of thermal conductivity between high and low thermal conductivity materials is or the bigger the scale factor of high conducting fin area to total area is, the better the heat transfer performance of disc becomes. When other parameters are fixed, there exists an optimal lengthwidth ratio of high conducting fins to achieve the minimum entransy dissipation rate of the disc. The dimensionless mean temperature difference of the disc decreases as the high conducting fin number increases and tends to a constant. The entransy dissipation rate is an index reflected the total heat transfer effect (mean temperature difference) of the disc, while maximum temperature difference is an index reflected a local heat transfer effect. The constructs based on entransy dissipation rate minimization is different from those based on minimization of maximum temperature difference. However, the changing tendencies of the optimal constructs obtained based on the two different objectives are identical with the changes of the number and area of the high conductivity material, and the reason for this is the nonlinear distribution of heat flux density in the disc.

(ii) Branch-patterned distribution of high-conductivity paths [157]. The cooling models of radial-patterned disc and the branch-patterned disc with first order assembly are shown in Figure 19, respectively. The heat current which is uniformly generated in the disc flows through the highconductivity paths towards the center of the disc. The rims of the discs are adiabatic. Compared the results based on entransy dissipation rate minimization with those based on maximum temperature difference minimization, it is found that the performance derived from the two optimization procedures are different. When the product of the thermal conductivity ratio and volume fraction is 30 , the critical dimensionless radius for adopting radial-patterned disc or the branch-patterned disc is 1.75 for the former procedure, while that is 2.18 for the latter procedure. Especially for the large dimensionless radius of the disc, the mean heat transfer temperature difference of the former procedure is lower than that of the latter procedure, which obviously improves the heat transfer performance of the disc.

\subsection{Optimization of round tube heat exchanger cross- section}

The round tube heat exchanger model is shown in Figure 20. The cross-section of round tube heat exchanger without high conducting fins is shown in Figure 21. The radius of the inner tube is $R_{\text {in }}$. Cold flow absorbs heat uniformly in the inner tube at the rate of $q_{\mathrm{in}}^{\prime \prime}$ per unit area. The radius of the outer tube is $R_{\text {out }}$. Hot flow releases heat uniformly in the cross-section between $R_{\text {in }}$ and $R_{\text {out }}$ (outer tube crosssection) at the rate of $q_{\text {out }}^{\prime \prime}$ per unit area. The thermal conductivity of the porous materials is $k_{0}$. Temperature gradient
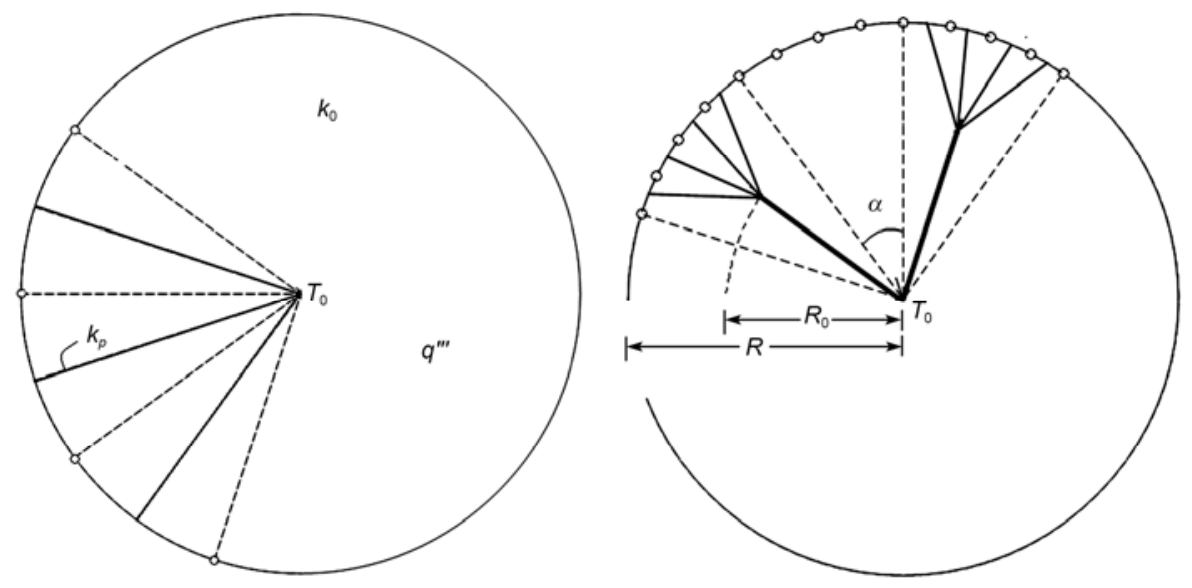

Figure 19 Radial-patterned disc and first order assembly of disc. 


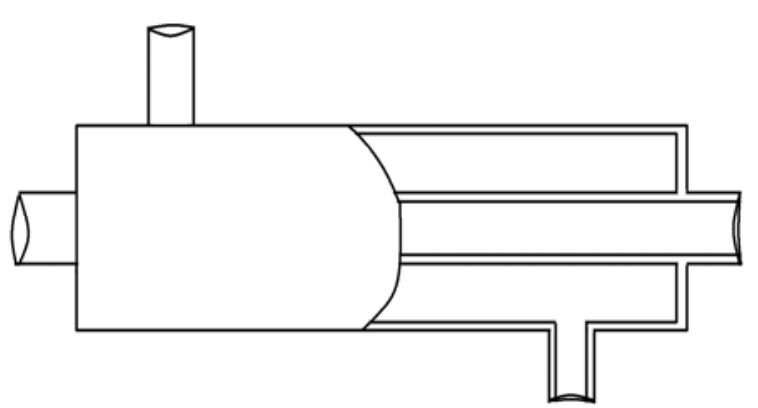

Figure 20 Round tube heat exchanger.

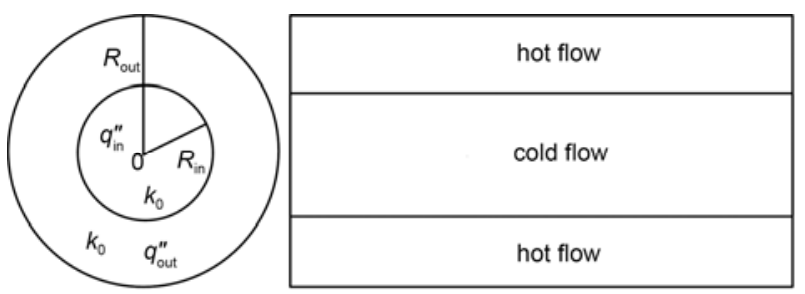

Figure 21 The cross-section of round tube heat exchanger without high conducting fins.

is along the radial distribution. The cross-section of round tube heat exchanger with high conducting fins is shown in Figure 22. By distributing a number of $(N)$ high conducting fins (thermal conductivity $k_{p}$ and width $D$ ), the cross-section is divided into $N$ parts.

The optimization results are shown in Figures 23 and 24. From Figures 23 and 24, the following conclusions can be obtained [158]:

(1) The heat transfer ability of the heat exchanger without high conducting fins is improved as the inner radius increases.

(2) Adding the right amount of high conducting fins can improve the performance of heat exchanger, but too many fins are not necessary.

\subsection{Multi-disciplinary and multi-objective optimization of electromagnet}

A cylindrical coil is taken as an example. Figure 25 shows the front and side views of the solenoid. A wire is wound in many layers around a cylindrical space with radius $R_{\text {in }}$. The outer radius of the coil is $R_{\text {out }}$, and the axial length is $2 L$.

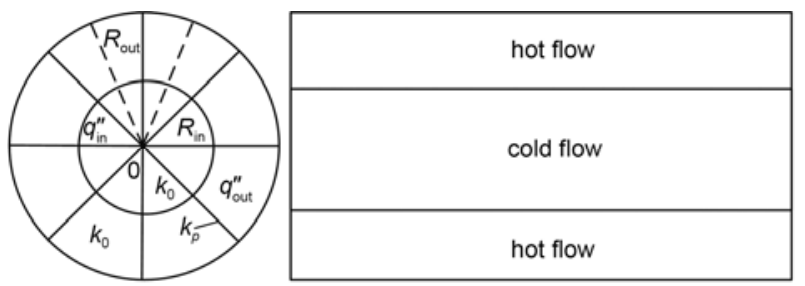

Figure 22 The cross-section of round tube heat exchanger with high conducting fins.

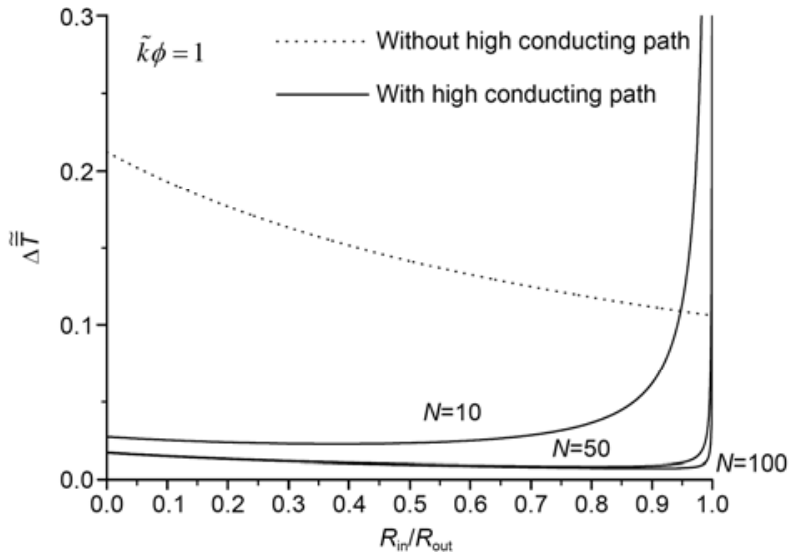

Figure 23 Effect of high conducting fins number on mean temperature difference versus the ratio of inner radius to outer radius with fixed high conducting material volume.

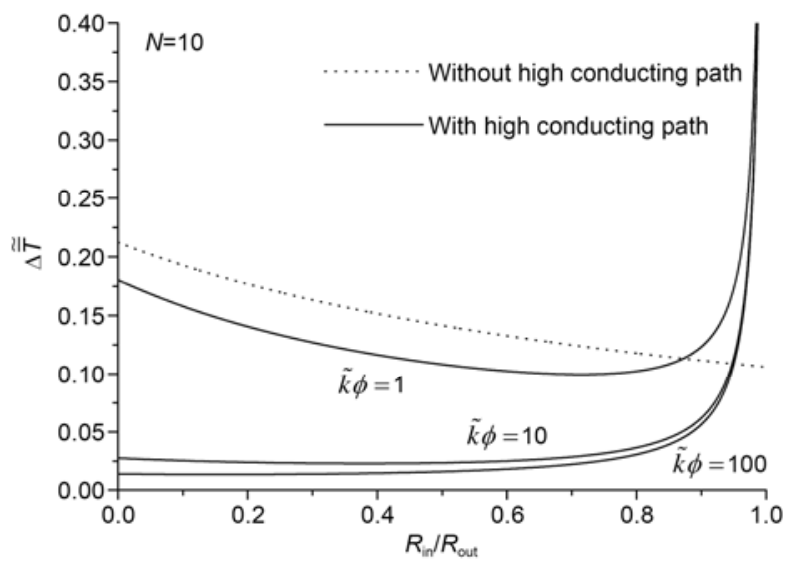

Figure 24 Effect of high conducting material volume on mean temperature difference versus the ratio of inner radius to outer radius with fixed high conducting fins number.

The electric current density inside the wire generates a onedimensional magnetic field on the axis of symmetry of the coil.

The heat generation rate per unit volume $q^{\prime \prime \prime}$ is constant at the working state. As illustrated in Figure 26, the high thermal conductivity cooling discs are inserted into the solenoid, and solenoid is divided into a number of $(N)$ subcoils.

(i) Constructal entransy dissipation rate minimization with fixed magnetic field [159]. Based on the concept of entransy dissipation, the expression of the mean temperature difference with high thermal conductivity material inserted in the solenoid (electromagnet) was deduced. The constructal optimization of electromagnet based on the extremum principle of entransy dissipation rate is firstly performed. The variation of minimum mean temperature difference with volume and magnetic field and the corresponding optimal constructs were shown. In addition, the effect of high thermal conductivity material on the magnetic field is analyzed. The optimization results show that for fixed magnetic field 


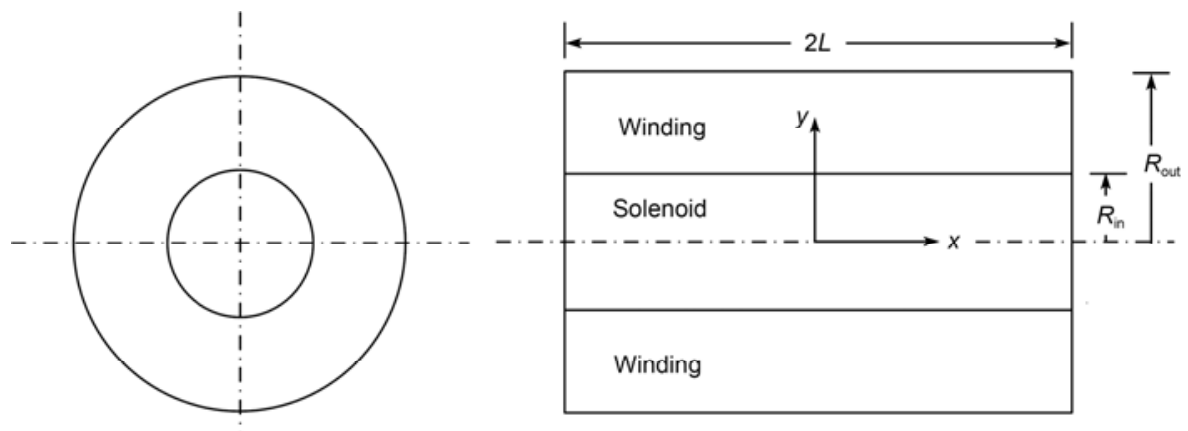

Figure 25 Main features of solenoid geometry.
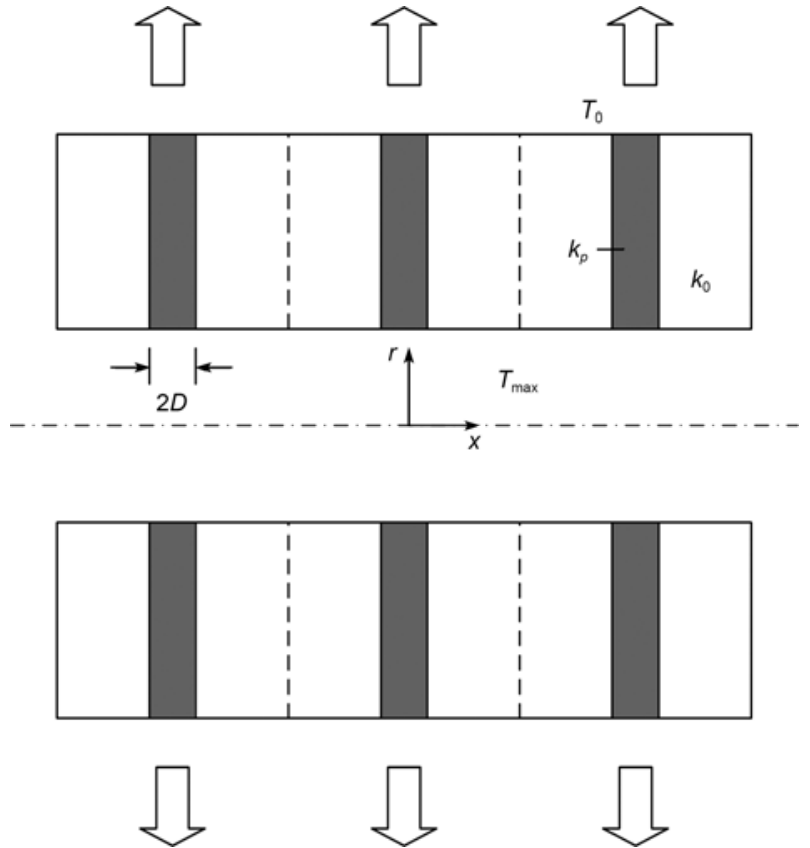

Figure 26 Solenoid cooled by transversal discs with high thermal conductivity.

and thermal conductivity, the minimum mean temperature difference decreases as the number $N$ of cooling discs increases, but the decrement of minimum mean temperature difference is relatively decreased. As $N$ increases, the radius of the solenoid decreases, the length of the solenoid increases, and the volume decreases. The solenoid optimized based on the minimization of entransy dissipation rate with fixed magnetic induction $\tilde{V}_{\text {opt }}$ is considerably larger than the winding optimized solely from the electromagnetic point of view. The mean temperature difference decreases as the volume increases.

(ii) Constructal complex-objective optimization of electromagnet based on magnetic induction and entransy dissipation rate [18]. The magnetic induction should be fixed firstly in the constructal optimization with specified magnetic induction based on entransy dissipation rate minimization. If the complex-objective function of entransy dissipa- tion rate and magnetic induction can be established, the constraint that magnetic induction is constant can be released. For electromagnet, the lower entransy dissipation rate is or the higher magnetic induction is, the better the performance of electromagnet becomes. Then, a complexobjective function to describe entransy dissipation rate and magnetic induction is defined as

$$
\frac{\tilde{G}}{\Delta \tilde{\bar{T}}}=\frac{0.2\left(\frac{2 \pi \tilde{L}}{\tilde{R}_{\text {out }}^{2}-1}\right)^{1 / 2} \ln \frac{\tilde{R}_{\text {out }}+\left(\tilde{L}^{2}+\tilde{R}_{\text {out }}^{2}\right)^{1 / 2}}{1+\left(\tilde{L}^{2}+1\right)^{1 / 2}}}{\left[\frac{\tilde{L}\left(\tilde{R}_{\text {out }}^{2}-1\right)}{6 N^{2} \pi}+\frac{\left(3-4 \tilde{R}_{\text {out }}^{2}+\tilde{R}_{\text {out }}^{4}\right)}{16 \tilde{k} \phi \pi \tilde{L}}+\frac{\left.\ln \tilde{R}_{\text {out }}\right]}{4 \tilde{k} \phi \pi \tilde{L}] \cdot \frac{1}{\left(\tilde{R}_{\text {out }}^{2}-1\right)^{2}}} .\right.}
$$

The constructal optimization results of electromagnet were compared with those based on the complex-objective function of maximum temperature difference and magnetic induction. The major conclusions are given as follows: for the linear distribution of heat flux in the electromagnet, the optimization results of constructal complex-objective optimization of electromagnet based on magnetic induction and entransy dissipation rate are the same as those based on the complex-objective function of maximum temperature difference and magnetic induction. When the electromagnet achieves its best performance, the best performance of electromagnet can be improved as the inserted number $N$ of the high thermal conductivity cooling discs increases; the solenoid becomes longer and thinner simultaneously, the magnetic induction increases, and both maximum temperature difference and mean temperature difference decrease. The best performance is also improved as $\tilde{V}$ increases. When $\tilde{V}$ increases, both the maximum temperature difference and mean temperature difference decrease, and the magnetic induction increases firstly and then decreases.

\subsection{Numerical optimizations of the cavity heat dissipa- tions}

In nucleate boiling, cavities always form between adjacent fins and may serve as promoters of vaporization, and 
vapotron effect between a refrigerant fluid with phase change and a non-isothermal finned surface also has been applied to cool electronic packages. In practical, heat transfer model of an open cavity intruding into a solid conducting wall exists widely in many modern engineering fields involving high heat flow density and large heat conduction, so the optimization for its global heat transfer performance is very important. For the numerical optimizations of the cavity heat dissipations, three models were studied: rectangular cavity with heat generation (Figure 27), rectangular cavity heated externally (Figure 28), and T-shaped cavity with heat generation (Figure 29).

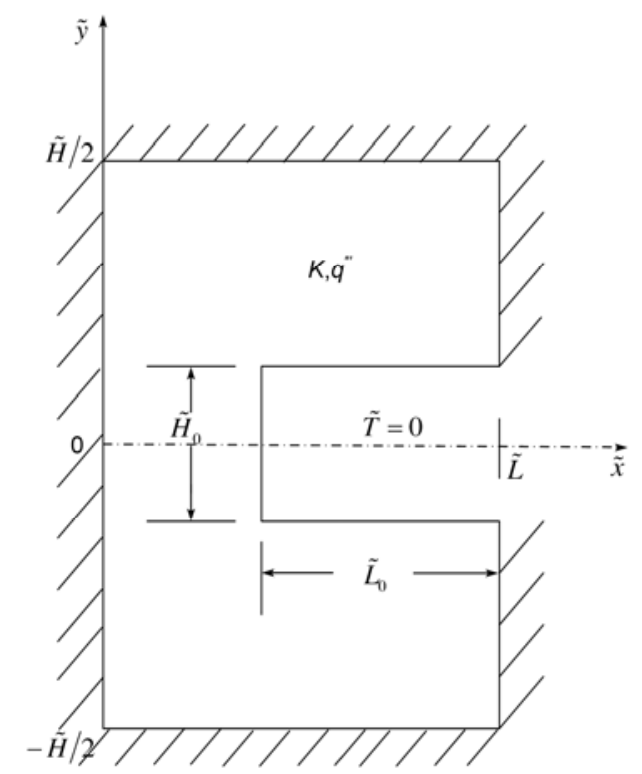

Figure 27 Rectangular cavity with heat generation.

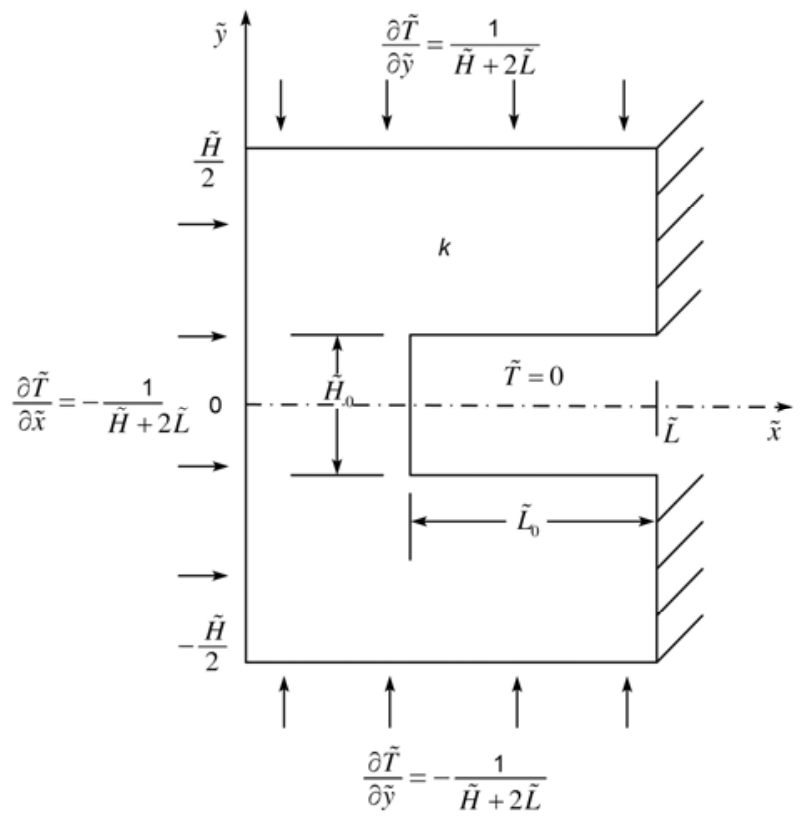

Figure 28 Rectangular cavity heated externally.

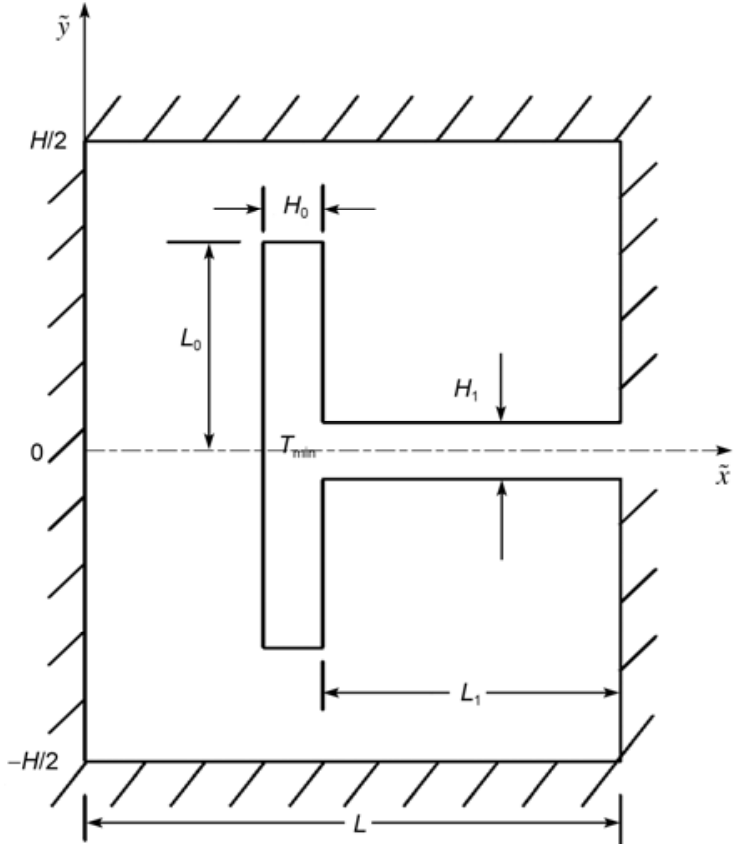

Figure 29 T-shaped cavity with heat generation.

The major conclusions were obtained as follows $[19,160$, 161]:

(1) Whether for the model with heat generation or that heated externally, there is no obvious difference between the two results based on minimizations of maximum thermal resistance and equivalent thermal resistance when the volume fraction $\Phi$ occupied by cavity is smaller, but the difference between the two results increases with the increases of $\Phi$ and the body aspect ratio $H / L$ for any model. Consequently, in the thermal design for some relevant problems, it is an intelligent decision to choose the optimal configuration with minimum equivalent thermal resistance and simultaneously to meet other necessary requirements, such as upper limit temperature (maximum thermal resistance).

(2) The optimal cavities for bodies heated externally are more slender than those for bodies with heat generation. Heat originating has obvious effect on the global performance of heat transfer. The entransy dissipation of body heated externally increases 2-3 times than that of body with heat generation, which indicates that the global performance of heat transfer weakens.

(3) When the volume fraction of the rectangle occupied by T-shaped cavity is limited, the equivalent thermal resistance and the maximum thermal resistance can not consequentially be reduced by merely increasing the volume of cooling cavity. For the fixed volume of cooling cavity, the equivalent thermal resistance and the maximum thermal resistance can effectively be reduced by reasonably designing the volume fraction of the rectangle occupied by T-shaped cavity in certain range. Compared the T-shaped cavity with the rectangular cavity, the entransy dissipation rate of the system can be further reduced. 


\section{Combination of entransy dissipation extre- mum principle with convection constructal opti- mization}

\subsection{Constructal optimization for cooling channel based on the entransy dissipation rate and flow-resistance minimizations}

By applying the entransy dissipation extremum principle to the constructal optimizations for the cooling channels of the heat-generating volume, the optimal constructs with minimum flow-resistances were obtained. As shown in Figure 30 , firstly, the rectangular element was optimized by minimizing entransy dissipation rate, and the optimal construct of the rectangular element was obtained. Secondly, based on the optimized rectangular element, the first-, second- and the third-order assemblies were optimized by minimizing global flow resistance. The optimal shape (or the optimal number of constituents) and the optimal thickness ratio $\left(\left(D_{i} /\right.\right.$ $\left.\left.D_{i-1}\right)_{\text {opt }}, i \geqslant 1\right)$ of the central channel and its tributaries of each order assembly were obtained. Finally, the element to the third order assembly with tapered channels are re-optimized. The optimization results are shown as follows [162,163]:

(1) For the constant channel, the minimum dimensionless global flow resistance of first-order assembly keeps constant. However, the decreasing amplitude of minimum dimensionless global flow resistance of second-order assembly is $32 \%$, and that of the third-order assembly is $54 \%$. The decreasing amplitude of minimum dimensionless global flow resistance grows greater as the order of each assembly becomes higher.

(2) For tapered channel, the minimum dimensionless global flow resistance of first-order assembly keeps constant. However, the decreasing amplitude of minimum dimensionless global flow resistance of second-order assembly is $37 \%$, and that of the third-order assembly is $60 \%$. The decreasing amplitude of minimum dimensionless global flow resistance grows greater as the order of each assembly becomes higher.

(3) Compared each order assembly with constant channels, the decreasing amplitude of the corresponding assembly with tapered channels is a little greater. It is shown that the more practical the assembly becomes based on the minimizations of entransy dissipation rate and flow-resistance, the greater the decreasing amplitude of minimum dimensionless global flow resistance of the assembly grows.

Therefore, it may create great superiority for constructal optimization to combine the entransy dissipation extreme principle with heat convection.

\subsection{Performance optimization for various kinds of as- semblies of fins and the steam generator}

Fin is an effective temperature control part or subassembly, which is applied widespread in the fields of energy, chemical engineering, astronavigation and electron. The constructal optimizations were performed for umbrella-shaped [164], T-shaped [165], Y-shaped [19], leaf-like [169] and tree-shaped assemblies [20] of fins by taking the minimization of entransy dissipation rate as optimization objective. Compared the optimal construct based on maximum thermal resistance minimization with that based on mean thermal resistance minimization, the mean temperature difference of the fin assembly can be obviously decreased, and the decreasing amplitude is high to $88.2 \%$ in a calculation case [165]. The heat transfer problem of the steam generator belongs to the entransy dissipation extremum principle with a fixed boundary temperature. The higher the entransy dissipation rate is, both the larger the mean heat flux and the better the heat transfer effect will be. That is, when the gas entransy dissipation rate is maximized, the mean heat flux in the heat transfer process will be maximized, and the
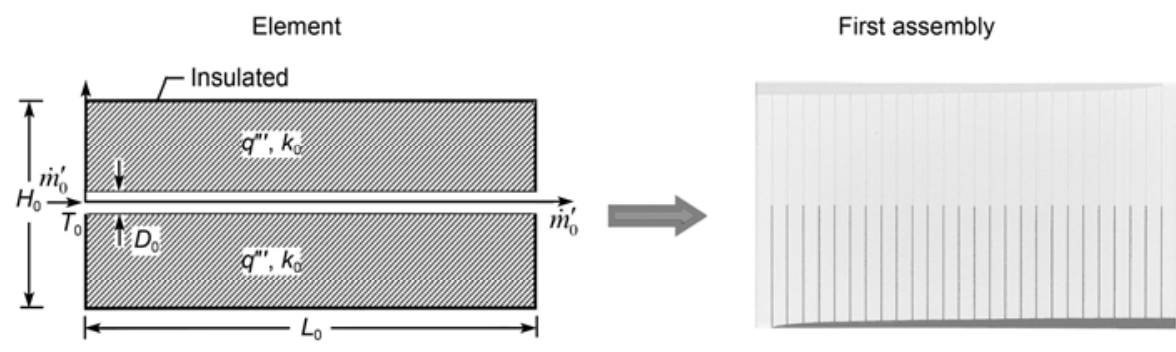

Second assembly

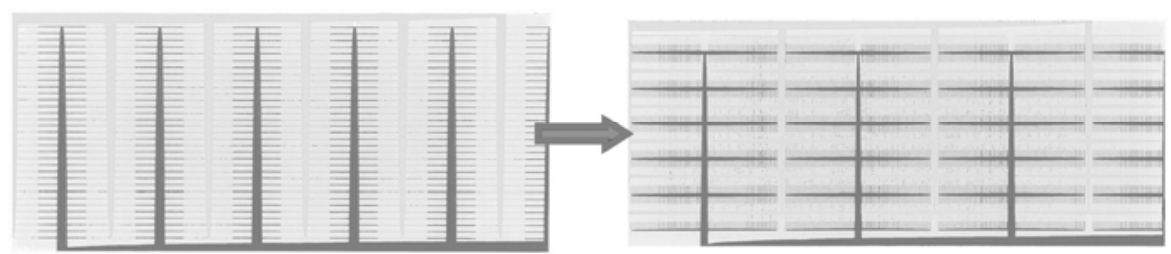

Figure 30 Constructal optimization of convection. 
performance of the system will be the best. Compared with the dimensionless mean heat flux based on heat transfer rate maximization, the dimensionless mean heat flux based on entransy dissipation rate maximization is increased by $58.7 \%$. Therefore, the optimal construct based on the latter objective improves the global heat transfer performance of the steam generator obviously [166].

\section{Conclusions}

The entransy theory provides a new theoretical fundament for heat transfer optimization, which is different from entropy generation minimization. Without the premise of taking work ability loss minimization as the objective, compared the entransy dissipation rate with entropy generation rate, the entransy dissipation rate is more suitable to describe heat transfer performance. The proposal of entransy and entransy dissipation extremum principle provides a new objective for heat transfer system optimization, which can be used to decsribe the total heat transfer ability of system [93]. The finite-time thermodynamic optimization of heat and mass transfer processes based on entransy dissipation extremum provided new results different from those obtained based on entropy generation rate optimization. The constructal optimization based on entransy dissipation rate extremum can preferably decrease the mean temperature difference in heat transfer process. When heat flux is linear distribution, entransy dissipation rate which is used to describe the total heat transfer ability of the system is linear with the maximum temperature difference which is used to describe the local heat transfer ability of the system. Furthermore, because the local and total heat transfer performances of heat transfer structure can not achieve their best simultaneously, to satisfy engineering demands, an optimization which considers local and total heat transfer performances simultaneously should be considered. For the real engineering heat transfer structure, it is considerable to take heat transfer safety into the optimizations [148,171]. It is foreseeable that, with the further expansions of the science research work, the application scope of entransy theory will be expanded, its scientific significance will be further clear, and its influence on thermal science will become enormous and profound.

This work was supported by the National Natural Science Foundation of China (51176203, 10905093).

1 Li Z X, Guo Z Y. Field Synergy Principle of Heat Convection Optimization(in Chinese). Beijing: Science Press, 2010

2 Guo Z Y, Cheng X T, Xia Z Z. Least dissipation principle of heat transport potential capacity and its application in heat conduction optimization. Chin Sci Bull, 2003, 48: 406-410

3 Guo Z Y, Liang X G, Zhu H Y. Entransy-A physical quantity describing heat transfer ability (in Chinese). Prog Nat Sci, 2006, 16: 1288-1296
4 Guo Z Y, Zhu H Y, Liang X G. Entransy-A physical quantity describing heat transfer ability. Int J Heat Mass Transfer, 2007, 50: 2545-2556

5 Guo Z Y. New physical quantities in heat (in Chinese). J Eng Thermophys, 2008, 29: 112-114

$6 \mathrm{Hu} \mathrm{G} \mathrm{J,} \mathrm{Guo} \mathrm{Z} \mathrm{Y.} \mathrm{The} \mathrm{efficiency} \mathrm{of} \mathrm{heat} \mathrm{transfer} \mathrm{process} \mathrm{(in} \mathrm{Chinese).}$ J Eng Thermophys, 2011, 32: 1005-1008

7 Cheng X T, Li Z X, Guo Z Y. Variational principles in heat conduction (in Chinese). J Eng Thermophys, 2004, 25: 457-459

8 China Association for Science Society of Academic Department. New Theory in Heat and Its Application- Proceedings of the Academic Salon for New Ideas and Theories (in Chinese). Beijing: China Science \& Technology Press, 2010

$9 \mathrm{Xu}$ M T. Entransy dissipation theory and its application in heat transfer. In: dos Santos Bernardes M A, ed. Developments in Heat Transfer. Rijeka, Croatia: InTech-Open Access Publisher, September 2011. Chapter 14. 247-272

10 Chen Q, Liang X G, Guo Z Y. Entransy-A novel theory in heat transfer analysis and optimization. In: dos Santos Bernardes M A,ed. Developments in Heat Transfer. Rijeka, Croatia: InTech-Open Access Publisher, September 2011. Chapter 19. 349-372

11 Li Z X, Guo Z Y. Optimization principles for heat convection. In: Wang L Q,ed. Advances in Transport Phenomena. Berlin: SpringerVerlag, 2011. 1-91

12 Meng $\mathrm{J}$ A. The heat transfer technology intensified by longitudinal vortices based on the field coordination theory and its applications (in Chinese). The Dissertation for the Doctoral Degree. Beijing: Tsinghua University, 2003

13 Cheng X G. Entransy and its applications in heat transfer optimization (in Chinese). The Dissertation for the Doctoral Degree. Beijing: Tsinghua University, 2004

14 Zhu H Y. The minimum thermal resistance principle based on entransy dissipation (in Chinese). The Dissertation for the Doctoral Degree. Beijing: Tsinghua University, 2007

15 Chen Q. Irreversibility and its optimization of convective heat transfer processes (in Chinese). The Dissertation for the Doctoral Degree. Beijing: Tsinghua University, 2008

16 Wu J. Potential energy (entransy) in thermal science and its applications (in Chinese). The Dissertation for the Doctoral Degree. Beijing: Tsinghua University, 2009

17 Liu X B. Entransy analysis of thermal performance for heat exchangers and cooling channel networks (in Chinese). The Dissertation for the Doctoral Degree. Beijing: Tsinghua University, 2009

18 Wei S H. Constructal entransy dissipation rate minimization for heat conduction (in Chinese). The Dissertation for the Doctoral Degree. Wuhan: Naval University of Engineering, 2009

19 Xie Z H. Multi-objective constructal optimizations for three classes of heat transfer structures (in Chinese). The Dissertation for the Doctoral Degree. Wuhan: Naval University of Engineering, 2010

20 Xiao Q H. Constructal optimizations for heat and mass transfer based on entransy dissipation extremum principle (in Chinese). The Dissertation for the Doctoral Degree. Wuhan: Naval University of Engineering, 2011

21 Guo J F. Thermodynamic analysis and optimization design of heat exchanger (in Chinese). The Dissertation for the Doctoral Degree. Jinan: Shandong University, 2011

22 Xia S J. Generalized thermodynamic dynamic optimization for irreversible processes and cycles (in Chinese). The Dissertation for the Doctoral Degree. Wuhan: Naval University of Engineering, 2012

23 Han G Z, Zhu H Y, Cheng X T, et al. Transfer similarity among heat conduction, elastic motion and electric conduction (in Chinese). J Eng Thermophys, 2005, 26: 1022-1024

24 Han G Z, Guo Z Y. Physical mechanism of heat conduction ability dissipation and its analytical expression (in Chinese). Proc CSEE, 2007, 27: 98-102

25 Zhu H Y, Chen J F, Guo Z Y. Electricity and thermal analogous experimental study for entransy dissipation extreme principle (in Chinese). Prog Nat Sci, 2007, 17: 1692-1698 
26 Cheng X T, Liang X G, Xu X H. Microscopic expression of entransy (in Chinese). Acta Phys Sin, 2011, 60: 060512

27 Cheng X T, Liang X G, Guo Z Y. Entransy decrease principle of heat transfer in an isolated system. Chin Sci Bull, 2011, 56: 847-854

$28 \mathrm{Hu}$ G J, Cao B Y, Guo Z Y. Entransy and entropy revisited. Chin Sci Bull, 2011, 56: 2974-2977

29 Liu W, Liu Z C, Jia H, et al. Entransy expression of the second law of thermodynamics and its application to optimization in heat transfer process. Int J Heat Transfer, 2011, 54: 3049-3059

$30 \mathrm{Xu} \mathrm{M} \mathrm{T.} \mathrm{The} \mathrm{thermodynamic} \mathrm{basis} \mathrm{of} \mathrm{entransy} \mathrm{and} \mathrm{entransy} \mathrm{dissipa-}$ tion. Energy, 2011, 36: 4272-4277

31 Cheng X T, Meng J A, Guo Z Y. Potential capacity dissipation minimization and entropy generation minimization in heat conduction optimization (in Chinese). J Eng Thermophys, 2005, 26: 1034-1036

32 Han G Z, Guo Z Y. Two different thermal optimization objective functions: dissipation of heat transport potential capacity and entropy production (in Chinese). J Eng Thermophys, 2007, 28: 811-813

33 Zhang Y C, Liu S T. Mathematical model of the optimal heat transfer structure design problem (in Chinese). Prog Nat Sci, 2008, 18: 680685

34 Chen Q, Wang M R, Pan N, et al. Irreversibility of heat conduction in complex multiphase systems and its application to the effective thermal conductivity of porous media. Int J Nonlinear Sci Numer Simul, 2009, 10: 57-66

35 Cheng X T, Xu X H, Liang X G. Homogenization of temperature field and temperature gradient field. Sci China Ser E-Tech Sci, 2009, 52: 2937-2942

36 Su X, Cheng X G, Meng J A, et al. Verification and characteristics of laminar field coordination equation (in Chinese). J Eng Thermophys, 2005, 26: 289-291

37 Su X, Meng J A, Cheng X G, et al. Optimal velocity field for laminar convection heat transfer in a cylinder and its application in engineering (in Chinese). J Tsinghua University (Science and Technology), 2005, 45: 677-680

38 Meng J A, Liang X G, Li Z X. Field synergy optimization and enhanced heat transfer by multi-longitudinal vortices flow in tube. Int $J$ Heat Mass Transfer, 2005, 48: 3331-3337

39 Wu J, Cheng X T, Meng J A, et al. Potential capacity dissipation extremum and entropy generation minimization in laminar convective heat transfer (in Chinese). J Eng Thermophys, 2006, 27: 100-102

40 Wei Q. Bounds on dissipation of heat transport potential capacity in turbulent convection with volume heat source (in Chinese). J Eng Thermophys, 2008, 29: 1354-1356

41 Cheng L, Xu M T. Entransy dissipation theory in convection heat transfer (in Chinese). In: Proceedings of Chinese Society of Engineering Thermophysics on Heat and Mass transfer. Zhengzhou: Chinese Society of Engineering Thermophysics, 2008, Paper No. 083278

42 Chen Q, Wu J, Ren J X. Thermodynamic optimization and heat transfer optimization for convective heat transfer (in Chinese). J Eng Thermophys, 2008, 29: 271-274

43 Chen Q, Wang M R, Pan N, et al. Optimization principles for convective heat transfer. Energy, 2009, 34: 1199-1206

44 Chen Q, Ren J X. Generalized thermal resistance for convective heat transfer and its relation to entransy dissipation. Chin Sci Bull, 2008, 53: 3753-3761

45 Wang S P, Chen Q L, Zhang B J. An equation of entransy and its application. Chin Sci Bull, 2009, 54: 3572-3578

46 Xu M T, Guo J F, Cheng L. Application of entransy dissipation theory in heat convection. Front Energy Power Engng China, 2009, 3: 402-405

47 Song W M, Meng J A, Li Z X. Optimization of flue gas convective heat transfer with condensation in a rectangular channel. Chin Sci Bull, 2011, 56: 263-268

48 Song W M, Meng J A, Li Z X. Optimization of flue gas turbulent heat transfer with condensation in a tube. Chin Sci Bull, 2011, 56: 1978-1984

49 Song W M, Meng J A, Liang X G, et al. Demonstration of uniformity principle of temperature difference field for one-dimensional heat exchangers (in Chinese). J Chemical Industry Eng, 2008, 59: 24602464

50 Cheng X T, Zhang Q Z, Liang X G. Analyses of entransy dissipation, entropy generation and entransy-dissipation-based thermal resistance on heat exchanger optimization. Appl Therm Eng, 2012, 38: 31-39

51 Liu X B, Guo Z Y, Meng J A. Entransy dissipation and thermal resistance analyses in heat exchanger (in Chinese). Prog Nat Sci, 2008, 18: 1186-1190

52 Liu X B, Guo Z Y. A novel method for heat exchanger analysis (in Chinese). Acta Phys Sin, 2009, 58: 4766-4771

53 Guo Z Y, Liu X B, Tao W Q, et al. Effectiveness-thermal resistance method for heat exchanger design and analysis. Int $\mathrm{J}$ Heat Mass Transfer, 2010, 53: 2877-2884

54 Xu M T, Cheng L, Guo J F. An application of entransy dissipation theory to heat exchanger design (in Chinese). J Eng Thermophys, 2009, 30: 2090-2092

55 Liu X B, Meng J A, Guo Z Y. Entropy generation extremum and entransy dissipation extremum for heat exchanger optimization. Chin Sci Bull, 2009, 54: 943-947

56 Guo J F, Cheng L, Xu M T. Entransy dissipation number and its application to heat exchanger performance evaluation. Chin Sci Bull, 2009, 54: 2708-2713

57 Chen L, Chen Q, Li Z, et al. Optimization for a heat exchanger couple based on the minimum thermal resistance principle. Int $\mathrm{J}$ Heat Mass Transfer, 2009, 52: 4778-4784

58 Chen Q, Wu J, Wang M R, et al. A comparison of optimization theories for energy conservation in heat exchanger groups. Chin Sci Bull, 2011, 56: 449-454

59 Qian X D, Li Z, Li Z X. Entransy-dissipation-based thermal resistance analysis of heat exchanger networks. Chin Sci Bull, 2011, 56: 3289-3295

60 Cheng X T, Liang X G. Computation of effectiveness of two-stream heat exchanger networks based on concepts of entropy generation, entransy dissipation and entransy-dissipation-based thermal resistance, Energy Convers Manage, 2012, 58: 163-170

61 Guo J F, Xu M T, Cheng L. Principle of equipartition of entransy dissipation for heat exchanger design. Sci China Tech Sci, 2010, 53: 1309-1314

62 Li M X, Chen L, Xu M T. Application of entransy dissipation theory in optimization design of shell-and-tube heat exchanger (in Chinese). J Eng Thermophys, 2010, 31: 1189-1192

63 Guo J F, Xu M T, Cheng L. Optimization design of plate-fin heat exchanger based on entransy dissipation number minimization (in Chinese). J Eng Thermophys, 2011, 32: 827-831

64 Guo J F, Xu M T, Cheng L. The entransy dissipation minimization principle under given heat duty and heat transfer area conditions. Chin Sci Bull, 2011, 56: 2071-2076

65 Guo J F, Xu M T, Cheng L. The influence of viscous heating on the entransy in two-fluid heat exchangers. Sci China Tech Sci, 2011, 54: 1267-1274

66 Guo J F, Xu M T, Cheng L. Effect of temperature-dependent viscosity on the entransy of both fluids in heat exchangers (in Chinese). Chin Sci Bull (Chin Ver), 2011, 56: 1934-1939

67 Li X F, Guo J F, Xu M T, et al. Entransy dissipation minimization for optimization of heat exchanger design. Chin Sci Bull, 2011, 56: 2174-2178

68 Qian X D, Li Z X. Analysis of entransy dissipation in heat exchangers. Int J Therm Sci, 2011, 50: 608-614

69 Wu J, Liang X G. Application of entransy dissipation extremum principle in radiative heat transfer optimization. Sci China Ser E-Tech Sci, 2008, 51: 1306-1314

70 Cheng X, Xu X H, Liang X G. Isothermal design for the space radiator (in Chinese). J Eng Thermophys, 2010, 31: 1031-1033

71 Cheng X T, Liang X G. Entransy flux of thermal radiation and its application to enclosures with opaque surfaces. Int J Heat Mass Transfer, 2011, 54: 269-278 
72 Cheng X, Xu X H, Liang X G. Radiative entransy flux in enclosures with non-isothermal or no-grey, opaque, diffuse surfaces and its application. Sci China Tech Sci, 2011, 54: 2446-2456

73 Cheng X T, Liang X G. Relationship between entransy dissipation of thermal radiation and homogenization of temperature field for thermal radiator in space (in Chinese). J Eng Thermophys, 2012, 33: 311-314

74 Chen Q, Ren J X. Mass transfer potential capacity dissipation extremum principle and decontamination ventilation optimization (in Chinese). J Eng Thermophys, 2007, 28: 505-507

75 Chen Q, Ren J X, Guo Z Y. Field synergy analysis and optimization of decontamination ventilation designs. Int $\mathbf{J}$ Heat Mass Transfer, 2008, 51: 873-881

76 Chen Q, Ren J X, Guo Z Y. The extremum principle of mass entransy dissipation and its application to decontamination ventilation designs in space station cabins. Chin Sci Bull, 2009, 54: 2862-2870

77 Chen Q, Meng J A. Field synergy analysis and optimization of the convective mass transfer in photocatalytic oxidation reactors. Int $\mathrm{J}$ Heat Mass Transfer, 2008, 51: 2863-2870

78 Chen Q, Yang K D, Wang M R, et al. A new approach to analysis and optimization of evaporative cooling system. I: Theory. Energy, 2010, 35: 2448-2454

79 Chen Q, Pan N, Guo Z Y. A new approach to analysis and optimization of evaporative cooling system. II: Applications. Energy, 2011, 36: 2890-2898

80 Yuan F, Chen Q. Optimization criteria for the performance of heat and mass transfer in indirect evaporative cooling systems. Chin Sci Bull, 2012, 57: 687-693

81 Chen L, Chen Q, Li Z, et al. Moisture transfer resistance method for liquid desiccant dehumidification analysis and optimization. Chin Sci Bull, 2010, 55: 1445-1453

82 Liu X B, Wang M R, Meng J A, et al. Minimum entransy dissipation principle for the optimization of transport networks. Int J Nonlinear Sci Numer Simul, 2010, 11: 113-120

83 Shan X D, Wang M, Guo Z Y. Geometry optimization of self-similar transport network. Math Problems in Eng, 2011, 421526

84 Liu X B, Chen Q, Wang M R, et al. Multi-dimensional effect on optimal network structure for fluid distribution. Chem Eng Processing: Process Intensification, 2010, 49: 1038-1043

85 Cheng X T, Xu X H, Ren J X, et al. Optimization of the thermal network in parallel connection (in Chinese). J Eng Thermophys, 2008, 29: 1985-1989

86 Cheng X, Xu X H, Liang X G. Application of entransy to optimization design of parallel thermal network of thermal control system in spacecraft. Sci China Tech Sci, 2011, 54: 964-971

87 Li Q Y, Chen Q. Application of entransy theory in the heat transfer optimization of flat-plate solar collectors. Chin Sci Bull, 2012, 57: 299-306

$88 \mathrm{Xu} \mathrm{Y} \mathrm{C,} \mathrm{Chen} \mathrm{Q.} \mathrm{An} \mathrm{entransy} \mathrm{dissipation-based} \mathrm{method} \mathrm{for} \mathrm{global}$ optimization of district heating networks. Energy Build, 2012, 48: 50-60

89 Cheng X T, Xu X H, Liang X G. Principles of potential entransy in generalized flow. Acta Phys Sin, 2011, 60: 118103

90 Cheng X T, Dong Y, Liang X G. Potential entransy and potential entransy decrease principle. Acta Phys Sin, 2011, 60: 114402

91 Guo Z Y, Cao B Y, Zhu H Y. State equation of phonon gas and conservation equations for phonon gas motion (in Chinese). Acta Phys Sin, 2007, 56: 3306-3312

92 Chen L G, Wei S H, Sun F R. Constructal entransy dissipation minimization of an electromagnet. J Appl Phys, 2009, 105: 094906

93 Chen Q, Zhu H Y, Pan N, et al. An alternative criterion in heat transfer optimization. Proc Royal Socity A, Mathematical, Physical Engineering Sci, 2011, 467: 1012-1028

94 Andresen B, Berry R S, Ondrechen M J, et al. Thermodynamics for processes in finite time. Acc Chem Res, 1984, 17: 266-271

95 Bejan A. Entropy generation minimization: The new thermodynamics of finite-size device and finite-time processes. J Appl Phys, 1996, 79: 1191-1218
96 Berry R S, Kazakov V A, Sieniutycz S, et al. Thermodynamic Optimization of Finite Time Processes. Chichester: Wiley, 1999

97 Chen L G, Wu C, Sun F R. Finite time thermodynamic optimization or entropy generation minimization of energy systems. J Non-Equilib Thermodyn, 1999, 24: 327-359

98 Chen L G, Sun F R. Advances in Finite Time Thermodynamics: Analysis and Optimization. New York: Nova Science Publishers, 2004

99 Chen L G. Finite Time Thermodynamic Analysis of Irreversible Processes and Cycles(in Chinese). Beijing: Higher Education Press, 2005

100 Wang J H, He J Z, Mao Z Y. Performance of a quantum heat engine cycle working with harmonic oscillator systems. Sci China Ser G-Phys Mech Astron, 2007, 50: 163-176

101 Song H J, Chen L G, Sun F R. Optimal configuration of a class of endoreversible heat engines for maximum efficiency with radiative heat transfer law. Sci China Ser G-Phys Mech Astron, 2008, 51: 1272-1286

102 Xia D, Chen L G, Sun F R. Optimal performance of a generalized irreversible four-reservoir isothermal chemical potential transformer. Sci China Ser B-Chem, 2008, 51: 958-970

103 Li J, Chen L G, Sun F R. Optimal configuration for a finite hightemperature source heat engine cycle with complex heat transfer law. Sci China Ser G-Phys Mech Astron, 2009, 52: 587-592

104 Xia S J, Chen L G, Sun F R. Optimal path of piston motion for Otto cycle with linear phenomenological heat transfer law. Sci China Ser G-Phys Mech Astron, 2009, 52: 708-719

105 Xia S J, Chen L G, Sun F R. Maximum power output of a class of irreversible non-regeneration heat engines with a non-uniform working fluid and linear phenomenological heat transfer law. Sci China Ser G-Phys Mech Astron, 2009, 52: 1961-1970

106 He J, He X, Tang W. The performance characteristics of an irreversible quantum Otto harmonic cycles. Sci China Ser G-Phys Mech Astron, 2009, 52: 1317-1323

107 Liu X W, Chen L G, Wu F R, et al. Ecological optimization of an irreversible harmonic oscillators Carnot heat engine. Sci China Ser G-Phys Mech Astron, 2009, 52: 1976-1988

108 Ding Z M, Chen L G, Sun F R. Thermodynamic characteristic of a Brownian heat pump in a spatially periodic temperature field. Sci China Phys Mech Astron, 2010, 53: 876-885

109 Ge Y L, Chen L G, Sun F R. Optimal paths of piston motion of irreversible Otto cycle heat engines for minimum entropy generation (in Chinese). Sci China Phys Mech Astron, 2010, 40: 1115-1129

110 Ding Z M, Chen L G, Sun F R. Modeling and performance analysis of energy selective electron (ESE) engine with heat leakage and transmission probability. Sci China Phys Mech Astron, 2011, 54: 1925-1936

111 Shu L W, Chen L G, Sun F R. The minimal average heat consumption for heat-driven binary separation process with linear phenomenological heat transfer law. Sci China Ser B-Chem, 2009, 52: 11541163

112 Xia S J, Chen L G, Sun F R. Maximum work configurations of finite potential reservoir chemical engines. Sci China Chem, 2010, 53: 1168-1176

113 Ma K, Chen L, Sun F. Optimal paths for a light-driven engine with linear phenomenological heat transfer law. Sci China Chem, 2010, 53: 917-926

114 Xia S J, Chen L G, Sun F R. Hamilton-Jacobi-Bellman equations and dynamic programming for power-optimization of multistage heat engine system with generalized convective heat transfer law. Chin Sci Bull, 2011, 56: 1147-1157

115 Xia S J, Chen L G, Sun F R. Optimization for entransy dissipation minimization in heat exchanger. Chin Sci Bull, 2009, 54: 3587-3595

116 Xia S J, Chen L G, Sun F R. Optimal paths for minimizing entransy dissipation during heat transfer processes with generalized radiative heat transfer law. Appl Math Modell, 2010, 34: 2242-2255

117 Xia S J, Chen L G, Sun F R. Entransy dissipation minimization for 
liquid-solid phase processes. Sci China Tech Sci, 2010, 53: 960-968

118 Xia S J, Chen L G, Sun F R. Entransy dissipation minimization for a class of one-way isothermal mass transfer processes. Sci China Tech Sci, 2011, 54: 352-361

119 Bejan A. Street network theory of organization in nature. J Advanced Transportation, 1996, 30: 85-107

120 Bejan A. Constructal-theory network of conducting paths for cooling a heat generating volume. Int J Heat Mass Transfer, 1997, 40: 799-816

121 Bejan A. Shape and Structure, from Engineering to Nature. Cambridge, UK: Cambridge University Press, 2000

122 Bejan A. Advanced Engineering Thermodynamics. 2nd ed. New York: Wiley, 1997

123 Bejan A, Dincer I, Lorente S, et al. Porous and Complex Flow Structures in Modern Technologies. New York: Springer, 2004

124 Rosa R N, Reis A H, Miguel A F. Bejan's Constructal Theory of Shape and Structure. Evora: University of Evora, 2004

125 Ingham D B, Bejan A, Mamut E, et al. Emerging Technologies and Techniques in Porous Media. Dordecht, The Netherlands: Kluwer Academic Publishers, 2004

126 Bejan A, Lorente S. The Constructal Law (La Loi Constructale). Paris: L' Harmatan, 2005

127 Bejan A, Lorente S, Miguel A F, et al. Along with Constructal Theory. University of Lausanne, Switzerland, 2006

128 Bejan A, Merkx G W. Constructal Theory of Social Dynamics. New York: Springer, 2007

129 Bejan A, Lorente S. Design with Constructal Theory. New Jersey: Wiley, 2008

130 Bejan A, Lorente S, Miguel A F, et al. Constructal Human Dynamics, Security \& Sustainability. Amsterdam: IOS Press, 2009

131 Bejan A. How nature takes shape: extensions of constuctal theory to ducts, river, turbulence, cracks, dendritic crystals and spatial economics. Int J Therm Sci, 1999, 38: 653-663

132 Bejan A. From heat transfer principles to shape and structure in nature: Constructal theory. Trans ASME, J Heat Transfer, 2000, 122: 430-449

133 Bejan A, Lorente S. Thermodynamic optimization of flow geometry in mechanical and civil engineering. J Non-Equilib Thermodyn, 2001, 26: $305-354$

134 Zhou S B, Chen L G, Sun F R. Constructal theory: A new direction for generalized thermodynamic optimization (in Chinese). J Therm Sci Tech, 2004, 3: 283-292

135 Bejan A, Lorente S. Constructal design and thermodynamic optimization. Annual Rev Heat Transfer, 2005, 14: 511-527

136 Lorente S, Bejan A. Svelteness, freedom to morph, and constructal multi-scale flow structures. Int J Therm Sci, 2005, 44: 1123-1130

137 Bejan A, Lorente S. Constructal theory of generation of configuration in nature and engineering. J Appl Phys, 2006, 100: 041301

138 Reis A H. Constructal theory: From engineering to physics, and how flow systems develop shape and structure. Appl Mech Rev, 2006, 59: 269-282

139 Bejan A, Marden J H. Unifying Constructal theory for scale effects in running, swimming and flying. J Exp Biol, 2006, 209: 238-248

140 Fan Y, Luo L. Recent applications of advances in microchannel heat exchangers and multi-scale design optimization. Heat Transfer Engng, 2008, 29: 461-474

141 Bejan A, Marden J H. The constructal unification of biological and geophysical design. Phys Life Rev, 2009, 6: 85-102

142 Bejan A, Lorente S. The constructal law of design and evolution in nature. Phil Trans R Soc B: Biol Sci, 2010, 365: 1335-1347

143 Bejan A, Lorente S. The constructal law and the design of the biosphere: Nature and globalization. Trans ASME, J Heat Transfer, 2011, 133: 011001

144 Wu W J, Chen L G, Sun F R. Improvement of tree-like network constructal method for heat conduction optimization. Sci China Ser E-Tech Sci, 2006, 49: 332-341

145 Zhou S B, Chen L G, Sun F R. Constructal optimization for solidgas reactors based on triangular element. Sci China Ser E-Tech Sci,
2008, 51: 1554-1562

146 Xie Z H, Chen L G, Sun F R. Constructal optimization of a vertical insulating wall based on a complex objective combining heat flow and strength. Sci China Tech Sci, 2010, 53: 2278-2290

147 Xie Z H, Chen L G, Sun F R. Constructal optimization of twice level Y-shaped assemblies of fins by taking maximum thermal resistance minimization as objective. Sci China Tech Sci, 2010, 53: 2756-2764

148 Chen L G, Xie Z H, Sun F R. Multiobjective constructal optimization of an insulating wall combining heat flow, strength and weight. Int J Therm Sci, 2011, 50: 1782-1789

149 Bejan A, Lorente S. The constructal law and the evolution of design in nature. Phys Life Rev, 2011, 8: 209-240

150 Chen L G. Progress in study on constructal theory and its application. Sci China Tech Sci, 2012, 55: 802-820

151 Wei S H, Chen L G, Sun F R. "Volume-point" heat conduction constructal optimization with entransy dissipation minimization objective based on rectangular element. Sci China Ser E-Tech Sci, 2008, 51: $1283-1295$

152 Wei S H, Chen L G, Sun F R. Constructal entransy dissipation minimization for "volume-point" heat conduction without the premise of optimized last-order construct. Int J Exergy, 2010, 7: 627-639

153 Wei S H, Chen L G, Sun F R. Constructal entransy dissipation minimization for "volume-point" heat conduction based on triangular element. Therm Sci, 2010, 14: 1075-1088

154 Wei S H, Chen L G, Sun F R. Constructal optimization of discrete and continuous-variable cross-section conducting path based on entransy dissipation rate minimization. Sci China-Tech Sci, 2010, 53: 1666-1677

155 Xiao Q H, Chen L G, Sun F R. Constructal entransy dissipation rate minimization for heat conduction based on variable-shaped element. Chin Sci Bull, 2011, 56: 2400-2410

156 Chen L G, Wei S H, Sun F R. Constructal entransy dissipation rate minimization of a disc. Int J Heat Mass Transfer, 2011, 54: 210-216

157 Xiao Q H, Chen L G, Sun F R. Constructal entransy dissipation rate minimization for "disc-to-point" heat conduction. Chin Sci Bull, 2011, 56: 102-112

158 Wei S H, Chen L G, Sun F R. Constructal entransy dissipation rate minimization of round tube heat exchanger cross-section. Int $\mathrm{J}$ Therm Sci, 2011, 50: 1285-1292

159 Wei S H, Chen L G, Sun F R. Constructal multidisciplinary optimization of electromagnet based on entransy dissipation minimization. Sci China Ser E-Tech Sci, 2009, 52: 2981-2989

160 Xie Z H, Chen L G, Sun F R. Constructal optimization for geometry of cavity by taking entransy dissipation minimization as objective. Sci China Ser E-Tech Sci, 2009, 52: 3504-3513

161 Xie Z H, Chen L G, Sun F R. Constructal optimization on T-shaped cavity based on entransy dissipation minimization. Chin Sci Bull, 2009, 54: 4418-4427

162 Xiao Q H, Chen L G, Sun F R. Constructal entransy dissipation rate and flow-resistance minimizations for cooling channels. Sci China Tech Sci, 2010, 53: 2458-2468

163 Xiao Q H, Chen L G, Sun F R. Constructal entransy dissipation rate minimization for a heat generating volume cooled by forced convection. Chin Sci Bull, 2011, 56: 2966-2973

164 Xiao Q H, Chen L G, Sun F R. Constructal entransy dissipation rate minimization for umbrella-shaped assembly of cylindrical fins. Sci China Tech Sci, 2011, 54: 211-219

165 Xie Z H, Chen L G, Sun F R. Comparative study on constructal optimizations of $\mathrm{T}$-shaped fin based on entransy dissipation rate minimization and maximum thermal resistance minimization. Sci China Tech Sci, 2011, 41: 962-970

166 Xiao Q H, Chen L G, Sun F R. Constructal design for a steam generator based on entransy dissipation extremum principle. Sci China Tech Sci, 2011, 54: 1462-1468

167 Chen L G, Wei S H, Sun F R. The area-point constructal entransy dissipation rate minimization for discrete variable cross-section conducting path. Int J Low-Carbon Tech, 2012, doi: 10.1093/ijlct/cts030 
168 Feng H J, Chen L G, Sun F R. "Volume-point" heat conduction constructal optimization based on entransy dissipation rate minimization with three-dimensional cylindrical element and rectangular and triangular elements at micro and nanoscales. Sci China Tech Sci, 2012, 55: 779-794

169 Feng H J, Chen L G, Sun F R. Constructal entransy dissipation rate minimization for leaf-like fins. Sci China Tech Sci, 2012, 55: 515526

170 Chen L G, Tian F H, Xiao Q H, et al. Constructal entransy dissipa- tion rate minimization for mass transfer based on rectangular element with constant channel (in Chinese). J Thermal Sci Tech, 2012, 11: 269-277

171 Xie Z H, Chen L G, Sun F R. Multi-objective constructal optimization of rectangular cavities based on complex function combining thermal resistances(in Chinese). In: Proceedings of Chinese Society of Engineering Thermophysics on Engineering Thermophysics and Energy Utilization. Nanjing: Chinese Society of Engineering Thermophysics, 2010, Paper No. 101033

Open Access This article is distributed under the terms of the Creative Commons Attribution License which permits any use, distribution, and reproduction in any medium, provided the original author(s) and source are credited. 